\title{
Signaling Networks Regulating Development of the Lower Respiratory Tract
}

\author{
David M. Ornitz and Yongjun Yin \\ Department of Developmental Biology, Washington University School of Medicine, St. Louis, Missouri 63110 \\ Correspondence: dornitz@wustl.edu
}

\section{SUMMARY}

The lungs serve the primary function of air-blood gas exchange in all mammals and in terrestrial vertebrates. Efficient gas exchange requires a large surface area that provides intimate contact between the atmosphere and the circulatory system. To achieve this, the lung contains a branched conducting system (the bronchial tree) and specialized air-blood gas exchange units (the alveoli). The conducting system brings air from the external environment to the alveoli and functions to protect the lung from debris that could obstruct airways, from entry of pathogens, and from excessive loss of fluids. The distal lung enables efficient exchange of gas between the alveoli and the conducting system and between the alveoli and the circulatory system. In this article, we highlight developmental and physiological mechanisms that specify, pattern, and regulate morphogenesis of this complex and essential organ. Recent advances have begun to define molecular mechanisms that control many of the important processes required for lung organogenesis; however, many questions remain. A deeper understanding of these molecular mechanisms will aid in the diagnosis and treatment of congenital lung disease and in the development of strategies to enhance the reparative response of the lung to injury and eventually permit regeneration of functional lung tissue.

\section{Outline}

1 Introduction

2 Embryonic origins of the lung

3 Formation of the distal respiratory tree
4 Regulation of lung size and shape

5 Perspectives

References

Editors: Patrick P.L. Tam, W. James Nelson, and Janet Rossant

Additional Perspectives on Mammalian Development available at www.cshperspectives.org

Copyright (C 2012 Cold Spring Harbor Laboratory Press; all rights reserved; doi: 10.1101/cshperspect.a008318

Cite this article as Cold Spring Harb Perspect Biol 2012;4:a008318 


\section{INTRODUCTION}

Lung development is commonly divided into five stages (embryonic, pseudoglandular, canalicular, saccular, and alveolar) (Figs. 1 and 2). The embryonic stage begins with the specification of progenitor cells in the foregut. Subsequent stages include morphogenesis of the proximal and distal conducting airways, formation of alveoli, and differentiation of cell types that are required for regionspecific functions of the lung, such as protection from foreign substances ( particles and pathogens), efficient movement of air into and out of the lung, and efficient gas exchange with the circulatory system (Thurlebeck 1995; Deutsch and Pinar 2002; Harpole and Aloia 2005; Joshi and Kotecha 2007; Warburton et al. 2010).

This review is intended to complement other reviews (Warburton et al. 2005, 2010; Cardoso and Lu 2006; Maeda et al. 2007; Cardoso and Kotton 2008; Morrisey and Hogan 2010; Domyan and Sun 2011; Rawlins 2011; Rock and Hogan 2011) by highlighting the key signaling pathways that regulate communication between epithelium, mesenchyme, and mesothelium during the early stages of lung development.

\section{EMBRYONIC ORIGINS OF THE LUNG}

The embryonic foregut gives rise to the respiratory tract, esophagus, stomach, intestine, liver, gallbladder, and pancreas. Development of the respiratory tract is initiated at embryonic day 9-9.5 in the mouse (Balfour 1881; Ten Have-Opbroek 1981; Kaufman 1992), 11-11.5 in the rat (Merei et al. 1997; Qi and Beasley 2000; Williams et al. 2003), and 22-26 in human (Dubreuil et al. 1936; Jeffrey 1998; Sadler 2010). The first morphogenetic event is the formation of the laryngotracheal grooves on the ventrolateral walls of the primitive foregut, which marks the formation of the tracheal diverticulum. The rostal (proximal) region of this "lung field" gives rise to the trachea and pharynx, and the caudal (distal) region gives rise to bulges (bronchial buds) that form the right and left bronchi (Fig. 1A). The bronchial buds follow a branching program that forms the proximal conducting airways and distal alveoli (Fig. 1B). Simultaneously, formation of the tracheoesophageal groove initiates septation of the foregut, allowing future independent elongation of the tracheal and esophageal tubes (Spooner and Wessells 1970; Williams et al. 2003).

The epithelial components of the lung and trachea arise from ventral endoderm, which are of distinct embryonic origins from the dorsal esophageal endoderm (Perl et al. 2002b; Brown and James 2009). Mesenchymal components of the respiratory tract also have distinct origins. Distal lung mesenchyme (mesenchymal, mesothelial, and vascular components of the lung that are distal to the terminal bronchioles) arises from the somatopleure rather than from centripetal growth of tracheal mesenchyme. In contrast, tracheobronchiolar mesenchyme (which gives rise to the connective tissue, cartilage, and smooth muscle components of the trachea and conducting airways and the proximal pulmonary vascular system) arises from splanchnic mesoderm (Brown and James 2009).

\subsection{Transcription Factors and Signaling Molecules Interact to Pattern the Foregut and Specify Where the Lung and Trachea Will Form}

The foregut is composed of an endodermal tube that is surrounded by mesenchyme and mesothelium (Fig. 1). Both endoderm and mesoderm contain patterning information, and both tissues are required to specify and initiate lung organogenesis. Explant experiments show that in the absence of mesoderm or mesoderm-specific signals, endoderm does not autonomously form a patterned branched structure. Tissue recombination experiments show that signals from the mesenchyme are essential for the formation of the lung buds and all subsequent stages of lung development. However, unspecified mesoderm from a variety of sources can initiate bud formation from the foregut, whereas distal (terminal bud) bronchial mesenchyme is required to induce later lung-specific epithelial branching (Spooner and Wessells 1970; Hilfer et al. 1985). Thus, mesenchyme derived from the developing lung contains additional information not found within the less differentiated mesenchyme.

Key regulatory molecules, which interact to pattern the foregut, specify the primary lung field, and regulate initial budding, are expressed in both mesoderm and endoderm. These factors include homeobox transcription factors (Hox), retinoic acid (RA), retinoic acid receptors, and mesenchymal- and endodermal-derived growth factors (Fig. 3A). Hox genes are expressed along the anterior-posterior axis in both endoderm and mesoderm and are proposed to have a primary role in the patterning of the foregut (Lazzaro et al. 1991; Bogue et al. 1996; Sakiyama et al. 2000). Hoxb5 and Nkx2.1 (thyroid transcription factor $1, T t f 1$ ) are expressed in the primary lung field and are required for subsequent stages of lung development. Hoxb5 is expressed in mesenchyme where it could regulate the expression of secreted factors that pattern the underlying endoderm (Krumlauf et al. 1987). However, inactivation of Hoxb5 alone does not affect primary lung bud formation (Rancourt et al. 1995), making it likely that functional redundancy exists with other Hox genes that have overlapping expression patterns with Hoxb5 (Bogue et al. 1996).

Nkx2.1 is one of the earliest markers of the lung endoderm (Lazzaro et al. 1991; Minoo et al. 1999). Nkx2.1 is first 


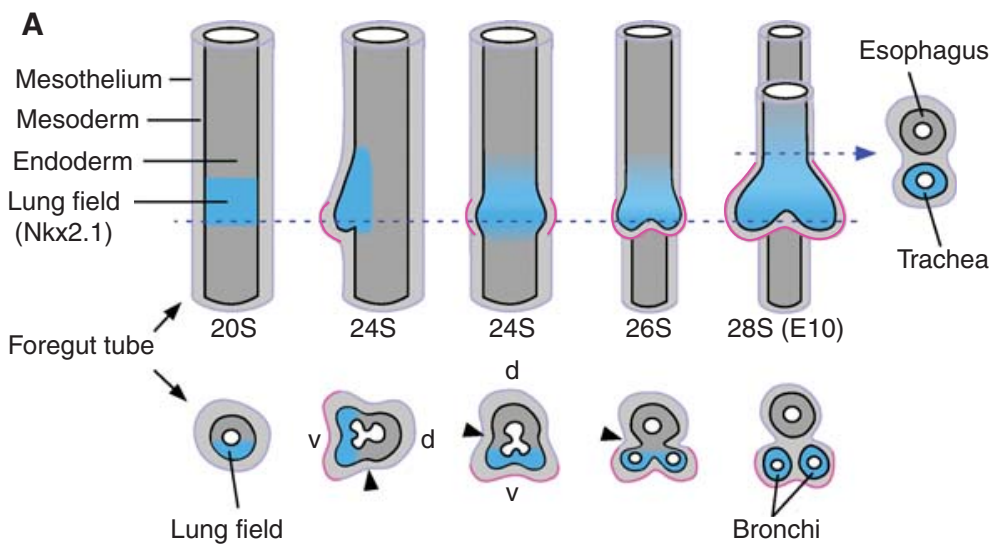

B
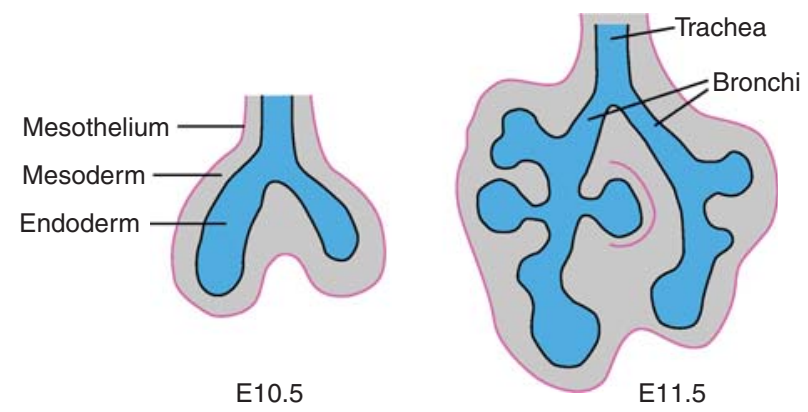

C
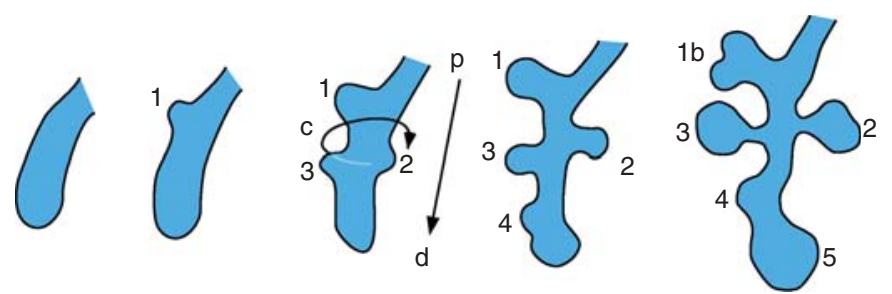

Figure 1. Morphogenesis of the bronchial tree. (A) The embryonic stage of lung development includes specification of the primary lung field and formation of lung buds ( primary bronchi) and trachea. The foregut tube is composed of endoderm, mesoderm, and the mesothelium (purple line). The mesothelium is an epithelial-like cell layer of mesodermal-derived cells that lines the surface of visceral organs within the coelomic cavity. Lung buds appear on the ventral (V) foregut at the 24 somite (24S) stage (E9.75 in the mouse). Before the appearance of lung buds, Nkx2.1 is expressed in ventral foregut endoderm (blue), marking the primary lung field. The tracheoesophageal groove (arrowhead) initiates septation of the anterior foregut and esophagus. The mesothelium associated with the lung buds (pink) will eventually give rise to the visceral pleura. Corresponding somite stages and embryonic ages are indicated. Arrowhead indicates the tracheoesophageal groove. Dashed line indicates the plane of cross section shown below and on the right. v, ventral; d, dorsal. (Adapted from Spooner and Wessells 1970). (B) Branching morphogenesis continues throughout the pseudoglandular stage (E10.5-E16.5 in the mouse) and gives rise to conducting airways and alveolar sacs. $(C)$ Primary lung lobes are formed by domain branching mechanisms and secondary subdivisions are formed by planar bifarcations. Domain branching regulates the temporal formation of buds along the proximal ( $\mathrm{p})$ - distal (d) axis (1-5) and their position on a circumferential axis (c). Domain branching is followed by orthogonal and planar bifurcations (1b) leading to iterative expansion of the endodermal structure of the lung.

expressed in the ventral endoderm of the foregut at E9.5 (Fig. 1A), and is also expressed in the developing thyroid and brain. Mice lacking $N k \times 2.1$ still form a trachea and lung buds; however, the buds fail to branch, and endodermal differentiation and expression of markers of differentiated lung epithelial cells fail to occur (Minoo et al. 1999).
Mechanisms that regulate where $N k \times 2.1$ is expressed are poorly understood; however, signaling through the Wnt/ $\beta$-catenin pathway in foregut endoderm is required for $N k \times 2.1$ expression and maintenance of respiratory fate (Harris-Johnson et al. 2009). More recently, it was shown that the Wnt ligands, Wnt2a (Wnt2) and Wnt2b, are 
D.M. Ornitz and Y. Yin

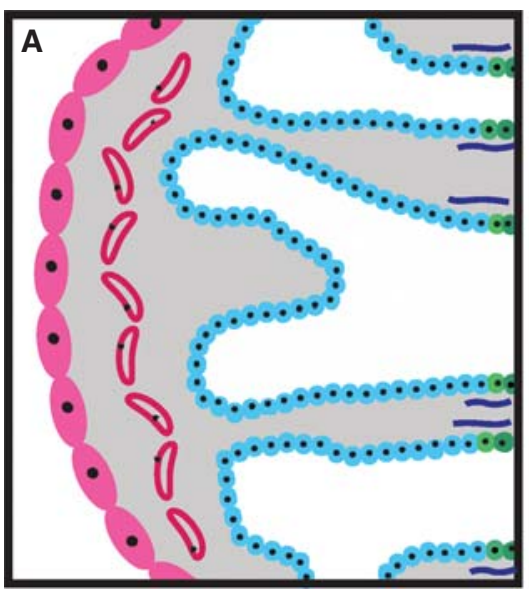

Pseudoglandular stage

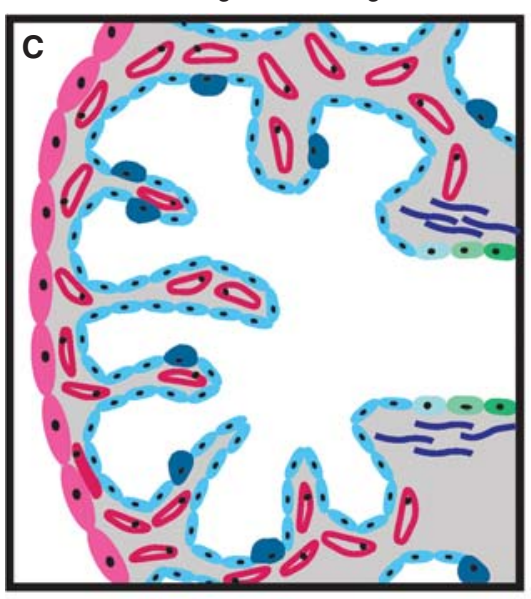

Saccular stage

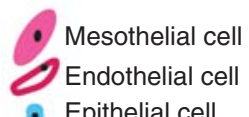

Epithelial cell

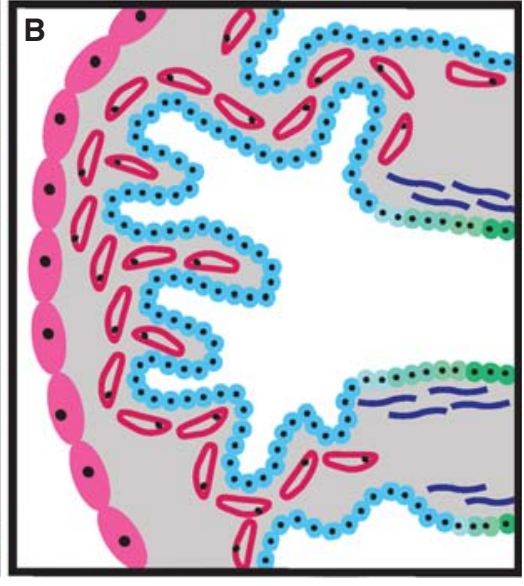

Canalicular stage

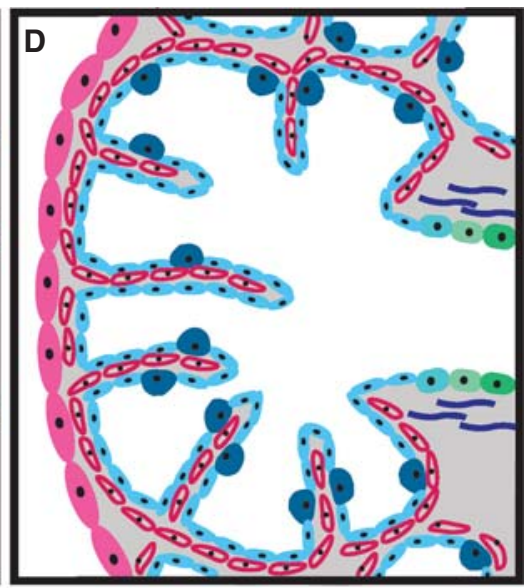

Alveolar stage

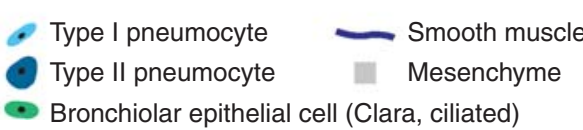

Figure 2. Stages of lung development. (A) The pseudoglandular stage (mouse E10.5 to 16.5; human E52 to week 17) begins with formation of secondary bronchi and includes formation of conducting airways, a primitive capillary plexus, and differentiation of mesenchyme to form smooth muscle. Histologically, this stage is characterized by glandularlike structures separated by abundant mesenchyme. (B) The canalicular stage (mouse E16.5 to 17.5; human wk 17 to 28 ) is characterized by thinning of the distal epithelium to form primitive pulmonary acini (terminal sacs), early differentiation of type I and type II pneumocytes (alveolar epithelial cells), and continued angiogenesis and juxtaposition of capillaries with the respiratory epithelium to increase gas exchange surface area. Mesenchyme in the canalicular stage is still relatively abundant. $(C)$ In the saccular stage (mouse E17.5 to postnatal (P) day 5; human wk 28 to 36), the terminal epithelial sacs continue to separate and become enveloped by capillaries. Type II pneumocytes begin to produce surfactant and continue to differentiate into type I pneumocytes. The submesothelial and subepithelial mesenchyme becomes thinner and contains more differentiated cells, including bronchiolar and vascular smooth muscle. (D) During the alveolar stage (mouse P5 to 30; human wk 36 to 40), the terminal epithelial sacs continue to form primary and secondary septa, creating mature alveoli.

expressed in ventral foregut mesenchyme at the developmental time when the lung is specified (Monkley et al. 1996; Zakin et al. 1998; Goss et al. 2009). Inactivation of $\beta$-catenin (Ctnnb1) in endoderm, or inactivation of the mesenchymal ligands Wnt2a and Wnt2b, resulted in complete absence of lung development (Fig. 3B,C) (Goss et al. 2009; Harris-Johnson et al. 2009).
In addition to $W n t 2 a$ and $W n t 2 b$, fibroblast growth factor $10(F g f 10)$ is expressed in mesenchyme adjacent to the sites of lung bud formation. Following formation of the primary lung buds, FGF10 is absolutely required for their initial outgrowth and survival (Bellusci et al. 1997; Min et al. 1998; Sekine et al. 1999; Weaver et al. 2000). FGF10 signals to FGF receptor $2 b$ (FGFR2b) in foregut endoderm 
A

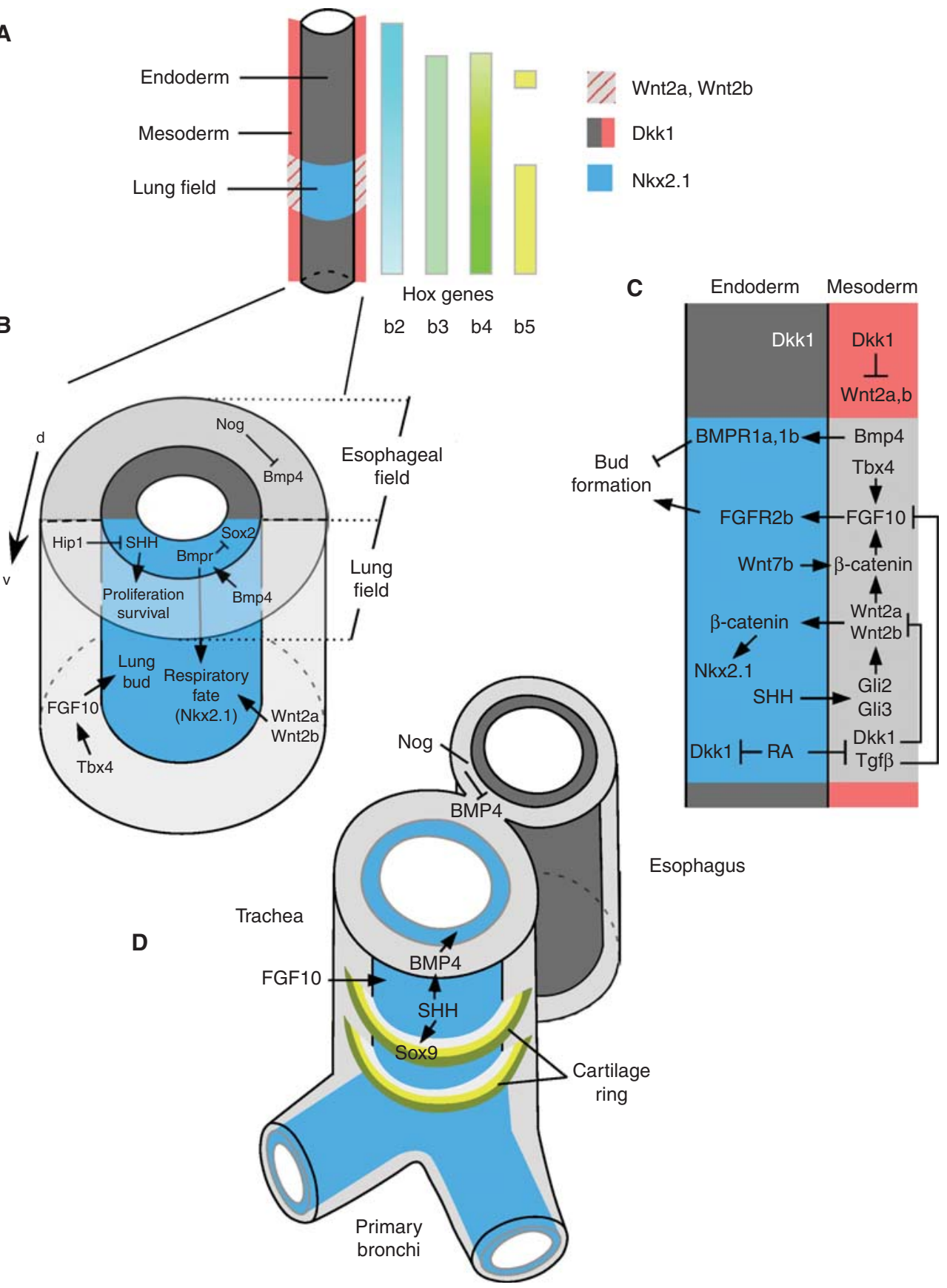

Figure 3. Signaling pathways regulating respiratory derivatives of the foregut. (A) Mesenchymal and endodermal molecules that pattern the foregut and lung field. $(B)$ Signaling molecules and key transcription factors that regulate lung bud formation. $(C)$ Signaling networks within and between endodermal and mesodermal components of the foregut that regulate lung bud formation. $(D)$ Signaling molecules that regulate morphogenesis of the trachea and esophagus.

(De Moerlooze et al. 2000; Abler et al. 2009). Because of the importance of FGF10 for the earliest stages of lung development, the mechanisms that regulate the timing, location, and activity of FGF10 are clearly critical (Fig. 3B,C).

T-box transcription factors $(T b x) 2,3,4,5$, and HoxA5 are expressed in foregut and lung mesenchyme, whereas
Tbxl is expressed in foregut endoderm (Chapman et al. 1996; Aubin et al. 1997; Gibson-Brown et al. 1998). The domain of Tbx4 overlaps with that of Fgf10, and inactivation of $T b x 4$ results in loss of $F g f 10$ expression and failure to form lung buds (Sakiyama et al. 2003). In addition to Tbx4, other mesenchymal factors that may directly regulate Fgf10 
expression include Wnt/ $\beta$-catenin, Hoxb5, and RA signaling (Wang et al. 2006; Volpe et al. 2007; Chen et al. 2010; Goss et al. 2011).

Bone morphogenetic protein $4(\mathrm{Bmp} 4)$ is expressed in ventral foregut mesenchyme at E9 (19 somite) (Weaver et al. 1999; Li et al. 2008; Danesh et al. 2009). At this stage, the primary role of Bmp4 is to promote proliferation of anterior foregut mesenchyme (shown by conditional inactivation of Bmp4 with Foxg1-Cre ${ }^{1}$ ). In subsequent stages of development, Bmp4 expression is restricted to endoderm (see below). During the embryonic stage of lung development (E9-E10.5), Bmp4 signaling is required for epithelial tube elongation but not for initial formation of the lung bud or specification of endoderm (expression of $N k \times 2.1$ ) (Li et al. 2008). However, Bmp4 signaling may restrict formation of lung buds because inactivation of BMP receptors 1a (Bmprla, Alk3) and 1b (Bmprlb, Alk6) in anterior ventral foregut endoderm (Shh-Cre ${ }^{2}$ ) resulted in ectopic lung bud formation (Domyan et al. 2011). Inactivation of only Alk3, in respiratory epithelial cells at a slightly later time using surfactant protein $\mathrm{C}(S f t p c)$ regulatory elements (Sftpc-rtTA/TetO-Cre, ${ }^{3,4}$ Sftpc-Cre ${ }^{5}$ ), resulted in decreased epithelial proliferation and reduced branching (Eblaghie et al. 2006; Sun et al. 2008). As discussed below, a consequence of loss of BMP signaling in foregut epithelium is tracheal agenesis.

Sonic hedgehog $(S h h)$ is expressed in the ventral foregut and tracheal diverticulum (Fig. 3B,C) (Litingtung et al. 1998). A primary role for hedgehog signaling in the $\mathrm{E} 9$ foregut is to promote mesenchymal proliferation and survival (Litingtung et al. 1998; Motoyama et al. 1998). Embryos lacking Shh show delayed formation of the primary lung buds and subsequent failure to branch (Pepicelli et al. 1998). The phenotype (failure to form primary lung buds) of mice lacking the hedgehog pathway transcription factors, Gli2 and Gli3, is more severe than that of mice lacking Shh (Motoyama et al. 1998). This suggests that other hedgehog molecules are involved or that Gli2 and Gli3 have additional hedgehog-independent functions (Motoyama et al. 1998). Additionally, Gli2 activator function and Gli3 repressor function may compensate for each

\footnotetext{
${ }^{1}$ FoxG1-Cre is expressed in the foregut endoderm as early as E8.5 and in endoderm and mesenchyme by E9.5 (Li et al. 2008).

${ }^{2}$ Shh-Cre contains a GFP-Cre fusion gene inserted into the Shh locus (Harfe et al. 2004). In the lung, the Shh-Cre allele is expressed exclusively in endoderm. ${ }^{3}$ The Sftpc-rtTA transgene targets expression of the reverse tetracycline transactivator protein (rtTA) to most lung endoderm by E10.5 (Perl et al. 2002a). In the presence of doxycycline, rtTA can activate tetracycline response elements (TetO) (Valencik and McDonald 2001).

${ }^{4} \mathrm{The} \mathrm{TetO}-\mathrm{Cre}$ transgene allele allows tetracycline-regulated expression of $\mathrm{Cre}$ recombinase (Perl 2002b).

${ }^{5}$ The Sftpc-Cre transgene drives Cre expression in lung endoderm (Okubo
} et al. 2005). other. Analysis of independent functions of Gli transcription factor signaling in the embryonic and early pseudoglandular stages indicate that Gli2 increases, and Gli3 decreases, Wnt2b expression (Pepicelli et al. 1998; Li et al. 2004). Possibly owing to the combined activator and repressor activities of Gli2 and Gli3, embryos lacking Shh have little effect on $W n t 2 b$ expression.

RA signaling is also essential for lung bud formation (Desai et al. 2004, 2006). Mice lacking retinaldehyde dehydrogenase 2 (Raldh2), but supplemented with RA from E7.5 to E8.5 to allow embryo development to progress, fail to develop lungs and do not express Fgf10 in foregut mesenchyme (Wang et al. 2006). The mechanisms by which RA signaling regulates Fgf10 expression are complex and indirect and appear to be mediated through Wnt and Tgf $\beta$ signaling pathways (Fig. 3C). The Wnt antagonist, $D k k 1$, is expressed throughout the foregut, but is excluded from the primary lung fields. In the foregut lung fields, RA signaling functions to suppress $D k k 1$ expression in mesoderm and endoderm. This allows increased Wnt signaling and up-regulation of $\mathrm{FgflO}$ (Chen et al. 2007, 2010). RA signaling also suppresses Tgf $\beta$ signaling in lung field mesenchyme (Chen et al. 2010). In mice that lack Raldh2, partial rescue can be achieved by activation of Wnt signaling (Chen et al. 2007); however, complete rescue requires simultaneous suppression of $\operatorname{Tgf} \beta$ signaling and activation of Wnt signaling (Chen et al. 2010). These studies suggest that both activation of Wnt signaling and suppression of Tgf $\beta$ signaling are required for $F g f 10$ expression in foregut mesenchyme and that RA signaling functions to coordinate the activity of these pathways (Chen et al. 2010).

\subsection{The Trachea and Esophagus Form by Septation of the Foregut Tube}

Soon after formation of the primary lung bud, the foregut begins to separate dorsoventrally into two parallel tubes, the esophagus and trachea (Figs. 1A and 3D). SHH and BMP signaling are required for growth of the trachea and separation of the tracheal and esophageal tubes. The transcription factor, $N k \times 2.1$, is also required for septation of the trachea and esophagus, and mice lacking $N k \times 2.1$ form a common tube between the pharynx and stomach (Minoo et al. 1999). The BMP antagonist, Noggin, is expressed in dorsal foregut mesenchyme where it opposes the activity of BMP4 (Fig. 3D). Bmp4 is expressed in ventral foregut mesenchyme (Weaver et al. 1999; Li et al. 2008) and inactivation of Bmp4 (Foxg1-Cre) resulted in agenesis of the tracheal tube (Li et al. 2008). However, in these conditional knockout embryos, at the 20-22 somite stage (E9.25), anterior endoderm still expressed Nkx2.1, showing that BMP4 signaling is not required for respiratory 
epithelial specification, but is required for outgrowth ( $\mathrm{Li}$ et al. 2008). Inactivation of Bmprla and Bmprlb in endoderm (Shh-Cre) resulted in a similar tracheal agenesis phenotype (Domyan et al. 2011). In embryos lacking endodermal BMP receptors (BMPRs), expression of $N k \times 2.1$ was significantly decreased in the anterior foregut endoderm by E10.5, consistent with a requirement of BMP signaling to maintain respiratory lineage differentiation. At this stage, the single endodermal tube lacked tracheal identity and expressed esophageal markers (Li et al. 2008).

Mice lacking Noggin $\left(\mathrm{Nog}^{-/-}\right)$have increased BMP signaling and show a phenotype opposite to that seen in the BMP pathway loss-of-function mutants. Seventy percent of mice lacking Noggin develop esophageal atresia or a tracheal-esophageal fistula (Que et al. 2006). Consistent with BMP signaling promoting the respiratory lineage, $\mathrm{Nog}^{-/-}$ mice show decreased growth of the esophagus, expanded expression of $N k \times 2.1$, and formation of cartilage in the posterior common gut tube. Thus, BMP signaling functions to promote respiratory cell fate in foregut endoderm.

Shh is expressed in the ventral foregut and at the highest levels in the tracheal diverticulum (Fig. 3B-D) (Litingtung et al. 1998). $S h^{-1-}$ embryos fail to form a distinct esophagus and trachea owing to failure to form the tracheoesophageal septum. In $\mathrm{Shh}^{-/-}$embryos, the common tube that extends to the stomach has predominantly tracheal morphology (Litingtung et al. 1998; Pepicelli et al. 1998; Miller et al. 2004). In the Shh ${ }^{-/-}$mutants, mesenchymal, but not endodermal, Bmp4 expression is decreased. At later stages, Shh functions downstream from Fgf10 and Fgfr $2 b$ to regulate patterning of Sox 9 expression and formation of the cartilaginous tracheal rings (Fig. 3D) (Miller et al. 2004; Park et al. 2010; Sala et al. 2011). Shh thus functions at multiple levels to promote respiratory fate in the foregut and regulate the separation between the esophagus and trachea.

\section{FORMATION OF THE DISTAL RESPIRATORY TREE}

\subsection{Stereotyped Branching Patterns in the Primary Lung Lobes}

The lung is subdivided into primary lobes or domains that are formed from branches off the primary bronchi. The branching pattern that forms these major subdivisions of the lung shows left-right asymmetry and is species specific. In humans, the left lung is composed of an upper (superior) and lower (inferior) lobe, whereas the right lung has a superior, middle, and inferior lobe (Gray 2000). In the mouse, the left lung is composed of only one lobe and the right lung is divided into four lobes: the caudal, cranial, middle, and accessory lobes. The patterning of these major divisions of the lung is regulated by a type of branching called domain branching (Metzger et al. 2008b).
The mechanisms that specify where domain branches will occur are not known; however, it is likely that this type of branching uses mechanisms that are distinct from those that control subsequent, more repetitive types of branching (Metzger et al. 2008b; Warburton 2008). Studies of the architecture of airway branch points revealed that there are two modes of domain branching coupled with a "periodicity generator" that specifies when a new branch will form and the spacing between branches (Metzger et al. 2008b). The first mode of domain branching regulates the location of buds along the proximal-distal axis, and the second mode regulates the position of buds on a circumferential axis (Fig. 1C). These mechanisms are discussed in more detail in Ochoa-Espinosa and Affolter (2012).

The left-right asymmetry of the lung that results from domain branching is ultimately controlled by earlier developmental mechanisms that regulate asymmetry of the embryonic axes (genes include nodal, Lefty 1 and 2, Pitx2, Hfh4 (Foxi1), and Gli2). Other genes act later in development to implement the asymmetric developmental program (Cardoso and Lu 2006; Warburton et al. 2010). Defects in some genes result in randomization of left and right sides of the body plan while maintaining asymmetry, whereas defects in other genes lead to loss of asymmetry (isomerization). For example, the lungs of $S h h^{-1-}$ embryos fail to branch beyond formation of the right and left primary lung buds, resulting in symmetric single left and right lobes (Pepicelli et al. 1998). Development of the lungs of $\mathrm{Gli}^{-/-}$embryos progresses farther than that of $\mathrm{Shh}^{-/-}$embryos, but still only form a single right lobe (Motoyama et al. 1998). Interestingly, loss of hedgehog interacting protein (Hip1), a negative regulator of hedgehog signaling, also results in a lung with only single left and right lobes instead of the normal four-lobed right lung (Chuang et al. 2003). Hip1 is expressed in mesenchyme, distal to where a branch will form. The underlying mechanism appears to be increased hedgehog signaling and suppression of Fgf10 expression in distal tip mesenchyme (Fig. 3B,C). In contrast to embryos with defects in the hedgehog signaling pathway, embryos lacking Pitx2 have four-lobed lungs on both the right and left side (Kitamura et al. 1999).

Even though the specific molecules that pattern branching have not been identified, it is clear that the formation of the initial domain branches and all subsequent branches are dependent on the expression of FgflO in mesenchyme distal to the branch point. Therefore, understanding the mechanisms that regulate where $F g f 10$ is expressed is thus critical for understanding how the bronchial tree is patterned (Warburton 2008). The primary sites of Fgf10 expression are hypothesized to be partially under the control of Hox family transcription factors, which are expressed in specific patterns throughout foregut and lung 
mesenchyme. In support of this idea, Hoxb3-b5 are expressed in foregut mesenchyme at E9.5 in the region where the lung buds will form (Fig. 3A), and Hoxb2-b5 are expressed in mesenchyme surrounding budding epithelium (Bogue et al. 1996). In an explant culture system, knockdown of Hoxb5 showed that it functions to localize the expression of Fgf10 in mesenchyme, and that it may also control Fgf10 signaling through regulation of extracellular matrix molecules (Volpe et al. 2007). In addition to Hox genes, the transcription factors $T b x 4$ and $T b \times 5$ are required for Fgf10 expression in lung field mesenchyme (CebraThomas et al. 2003; Sakiyama et al. 2003). RA, which is required for Fgf10 expression and formation of the primary lung buds, must be down-regulated in distal tip mesenchyme for Fgf10-dependent secondary branching to occur (Malpel et al. 2000).

\subsection{Molecular Mechanisms Regulating Branching Morphogenesis}

The formation of the terminal branching pattern of conducting airways uses the two domain-branching mechanisms (proximal-distal and circumferential), and also implements two types of tubular bifurcations (planar and orthogonal) (Metzger et al. 2008b). The precise mechanisms that specify which modes of branching will occur are not known. However, it is clear that these patterning mechanisms must regulate intrinsic and extrinsic signals that specify the location of branch points through the regulation of epithelial proliferation, cell shape, cell division planes, and movement. These cellular events are controlled by the dynamic interaction of signaling molecules, inhibitors, receptors, and the extracellular matrix within a "signaling center" comprised of distal airway epithelium, surrounding mesenchyme, and the overlying mesothelium (Fig. 3A) (Cardoso 2000; Warburton et al. 2005; Cardoso and Lu 2006; Morrisey and Hogan 2010).

One "hard-wired" genetic program that could guide the stereotyped branching pattern of the lung may involve specification of regional identity of lung mesenchyme by Hox transcription factors (Bogue et al. 1996). During early pseudoglandular stage development (E10.5-E14.5), there are two patterns of Hoxb gene expression. Hoxb3 and Hoxb4 are expressed in proximal and distal lung mesenchyme, whereas Hoxb2 and Hoxb5 messenger RNA (mRNA) are only expressed in distal lung mesenchyme (Bogue et al. 1996). Sakiyama showed that expression domains of Hoxb6-Hoxb9 correspond to the morphological subdivisions of the air sacs along the proximodistal axis and that dorsal and ventral pulmonary mesenchyme, demarcated by Hoxb6 expression, have different inductive capacities toward the tracheal epithelium (Sakiyama et al. 2000). Future genetic experiments in which multiple Hox genes are inactivated will be required to determine the extent to which they influence branching patterns of the respiratory tree.

\subsubsection{Progenitor Cells Positioned along the Proximodistal Axis Give Rise to Differentiated Cells in the Alveoli and Conducting Airways}

Lung epithelial progenitor cells are thought to reside in the distal tip region of the developing respiratory bud (Rawlins et al. 2009). As the lung matures and daughter cells assume more proximal positions along the respiratory tree, they differentiate into multiple cell types that populate the distal (alveolar) and proximal (conducting) airways (Rawlins et al. 2008; Rock and Hogan 2011). The alveolar compartment contains type II pneumocytes (also called alveolar epithelial type 2 cells, AEC2) that are the primary source of surfactant proteins. Type II cells also give rise to type I pneumocytes (also called alveolar epithelial type 1 cells, AEC1), which are marked by the expression of aquaporin 5. Type I pneumocytes are thin cells that constitute the majority of the alveolar surface area (98\% in the mouse) and function to mediate efficient gas exchange with juxtaposed capillary endothelial cells (Stone et al. 1992). The conducting airways are lined by Clara, ciliated, neuroendocrine and basal cells. More proximal conducting airways also contain mucus-producing goblet cells. Clara cells express secretoglobulins such as Clara cell secretory protein (CCSP or CC10); neuroendocrine cells produce neuropeptides such as calcitonin. During development, a Clara-like cell can give rise to both ciliated and neuroendocrine cells, and the ratio of these two cell types is governed by Notch signaling (Tsao et al. 2009). In mature lungs, cells with progenitorlike properties include type II alveolar epithelial cells, cells located in the bronchoalveolar duct junction (BADJ) and the basal cells along conducting airways (Giangreco et al. 2002, 2009; Kim et al. 2005).

\subsubsection{Autocrine and Paracrine Signals Interact to Regulate Epithelial Cell Proliferation}

Lung epithelial cells express receptors for FGF10 ( Fgfr2b), BMP4 (Bmprla/Alk3 and Bmpr1b), the canonical Wnt ligand, Wnt7b (Fzd10), and the noncanonical Wnt ligands, Wnt5a (Fzd2) (Wang et al. 2005; Eblaghie et al. 2006; Zhang et al. 2008) and Wnt11 (Lako et al. 1998). Of these, the BMP signaling pathway has been shown to regulate epithelial proliferation during pseudoglandular stage lung development. During this stage, Bmp4 expression is restricted to the epithelium at the tip of the lung buds (Weaver et al. 1999; Jang et al. 2010). Conditional inactivation of Bmprla, expression of BMP antagonists, or conditional 
haploinsufficiency of Bmp4 in lung epithelium (Sftpc-Cre) results in decreased epithelial proliferation and increased apoptosis (Weaver et al. 1999; Eblaghie et al. 2006). Thus, BMP4 functions as an autocrine growth factor for lung epithelium. Extrinsic regulation of BMP4 signaling appears to be mediated by the BMP antagonists, Noggin (Nog) and Gremlin (Grem1), which are expressed in adjacent mesenchyme (Weaver et al. 1999, 2003; Shi et al. 2001). Knockdown of Grem1 in explant cultures with antisense oligonucleotides resulted in increased epithelial proliferation and increased differentiation (expression of $S f t p c$ ) (Shi et al. 2001). Gremlin 1 knockout mice $\left(G r e m 1^{-/-}\right)$die at birth with defects in alveolar septation, as well as a multilayered epithelium (Michos et al. 2004). Noggin knockout mice $\left(\operatorname{Nog}^{\mathrm{LacZ} / \mathrm{LacZ}}\right)$ have abnormal truncations of lung lobes but no other reported lung phenotypes (Brunet et al. 1998; McMahon et al. 1998; Weaver et al. 2003). Functional redundancy between Grem 1 and Noggin has not been investigated.

Wnt signaling also regulates epithelial proliferation, although indirectly. Mouse embryos that are null for Wnt7b show decreased epithelial and mesenchymal proliferation primarily in the region of the distal epithelial tip without any increase in cell death (Rajagopal et al. 2008). Wnt7b likely signals to epithelial Fzd10 and mesenchymal Fzd1 (Wang et al. 2005). The pathway through which canonical Wnt7b signaling regulates epithelial proliferation appears to be mediated through mesenchyme. Inactivation of epithelial $\beta$-catenin did not affect epithelial proliferation but rather impaired distal differentiation (Mucenski et al. 2003). Furthermore, Bmp4 expression was normal in the epithelium of lungs lacking $W n t 7 b$ or epithelial $\beta$-catenin (Mucenski et al. 2003; Shu et al. 2005). However, inactivation of mesenchymal $\beta$-catenin resulted in decreased epithelial proliferation, probably through derepression of mesenchymal noggin and resulting inhibition of Bmp4 signaling (Fig. 4A) (Yin et al. 2011).

Wnt5a is expressed in lung epithelium and adjacent mesenchyme and at highest levels around the distal tip ( $\mathrm{Li}$ et al. 2002). Wnt5a signals through the noncanonical receptor Fzd2 (Sato et al. 2010). Inactivation of Fzd2 or Gata6 (which regulates Fzd2) resulted in increased epithelial proliferation, increased $B m p 4$ expression, and increased canonical Wnt signaling (Fig. 4B) (Bellusci 2008; Zhang et al. 2008). However, Wnt5a- $a^{-1}$ lungs showed no change in epithelial proliferation or apoptosis during pseudoglandular stages (E13.5) (Li et al. 2005), but increased proliferation during saccular stages (E18.5) (Li et al. 2002).

FGF10 signaling enhances epithelial proliferation (Bellusci et al. 1997; Weaver et al. 2000; Ramasamy et al. 2007); however, this activity is independent of PI3K and p-Erk activation (Metzger et al. 2007; Tang et al. 2011). Therefore, the effects of FGF10 on epithelial proliferation may be mediated through other FGFR signaling pathways (such as $\gamma$ PLC) or indirectly through FGF10/FGFR2b-induced increases in the expression of Bmp4 (Lebeche et al. 1999; Weaver et al. 2000; Hyatt et al. 2004), a known regulator of epithelial proliferation.

\subsubsection{Secreted Morphogens Have a Key Role in Regulating Epithelial Branching and Differentiation}

FGF10 signaling to FGFR2b is required for formation of epithelial buds throughout embryonic and pseudoglandular stages of lung development (Figs. 3C and 4B) (Min et al. 1998; Sekine et al. 1999; Ramasamy et al. 2007; Abler et al. 2009). Studies on the mechanisms of bud formation indicate that initial bud outgrowth occurs independent of proliferation and then, after bud initiation, proliferation increases in distal epithelium (Nogawa et al. 1998). Consistent with this, FGF10 has been shown to induce chemotaxis toward the source of FGF10, as well as having some mitogenic activity on lung epithelial explants (Bellusci et al. 1997; Weaver et al. 2000; Hyatt et al. 2004; Li et al. 2005). FGF10 also promotes distal cell fate, and inactivation of FGF10/FGFR2b signaling leads to expansion of proximal cells that express Sox2 and loss of distal epithelial cells that express Sox9 (Abler et al. 2009). It is not known whether this effect on epithelial differentiation is direct or mediated through another pathway. Consistent with the latter model, FGF10 signaling is required for epithelial canonical Wnt signaling (Ramasamy et al. 2007), which functions to regulate distal epithelial differentiation (Mucenski et al. 2003).

FGF9 signaling also contributes to epithelial branching (Fig. 4C). Although epithelial-expressed FGF9 signals to lung mesenchyme (see below), it also can signal directly to lung epithelium where it affects epithelial morphology and promotes branching (del Moral et al. 2006a; White et al. 2006; Yin et al. 2008, 2011). Effects of FGF9 on branching could be mediated through induction of $D k k 1$ expression and inhibition of Wnt signaling in distal lung epithelium (del Moral et al. 2006a). Canonical Wnt signaling within lung endoderm is required for distal epithelial differentiation and branching (Mucenski et al. 2003; Shu et al. 2005) and inhibition of Wnt signaling by overexpression of Dkk1-blocked distal epithelial differentiation and fibronectin expression (De Langhe et al. 2005). Interestingly, fibronectin is essential for formation and stabilization of the branch cleft (Sakai et al. 2003).

FGF signaling is negatively regulated by Sprouty (Spry) genes and Spryl, 2, and 4 are expressed in distal tip epithelium, adjacent to where Fgflo is expressed in mesenchyme (Fig. 4B) (Zhang et al. 2001; Hashimoto et al. 2002). 
A

A
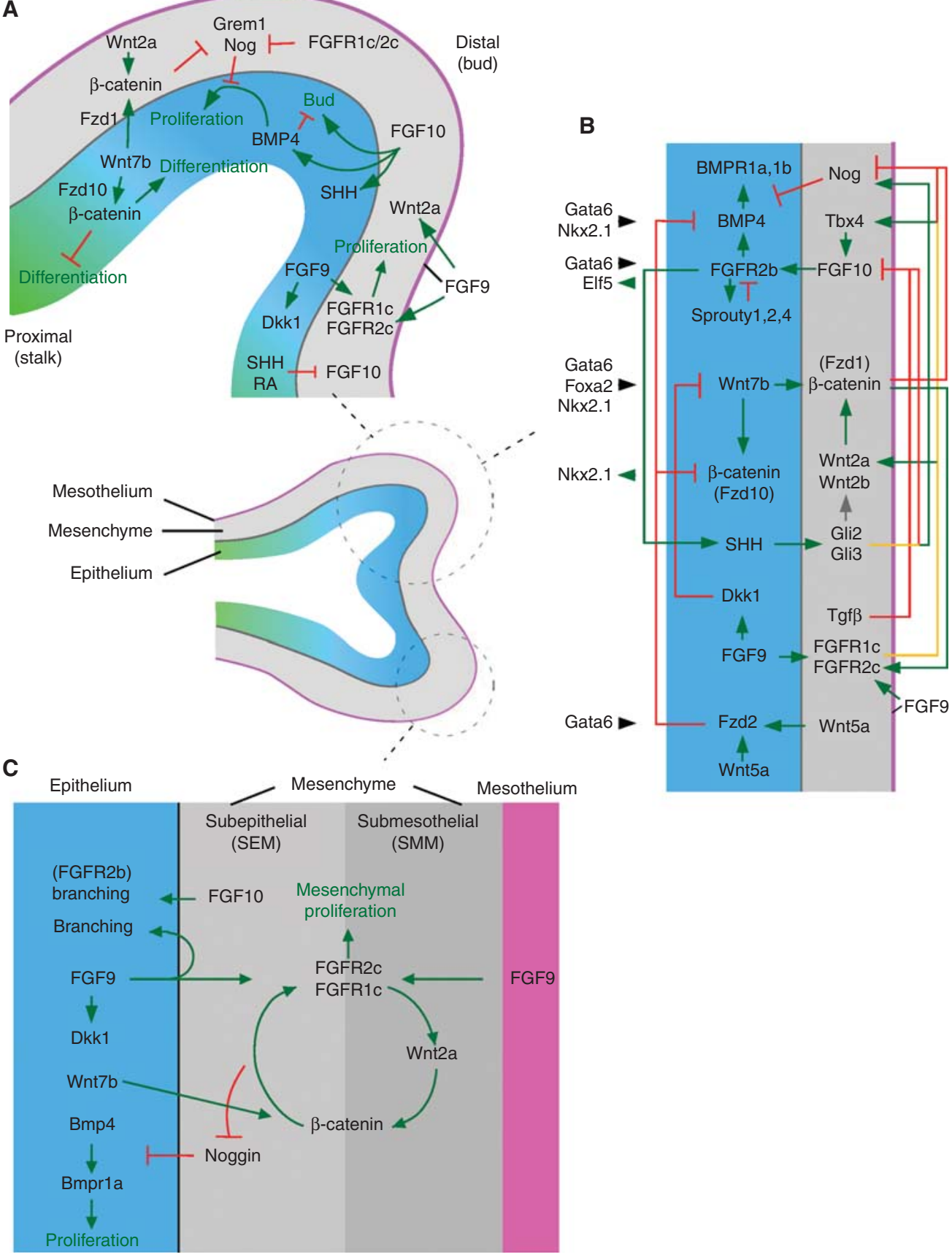

Figure 4. Signaling pathways regulating lung development at the early (E12.5) pseudoglandular stage. (Center) Diagram showing a branching epithelial tube (distal, blue and proximal, green) surrounded by mesenchyme (gray) and mesothelium (pink). (A) Signaling molecules that regulate growth, budding, and differentiation of the airway epithelium and surrounding mesenchyme. (B) Signaling network model of the distal lung bud. (C) Feed-forward signaling network within subepithelial and submesothelial mesenchyme.

Inactivation of Spry1 and/or Spry2 results in increased branching, differentiation toward distal airway cell types, and epithelial dilation (Tefft et al. 1999; Taniguchi et al. 2007; Tang et al. 2011). Inactivation of Spry2 and Spry4 resulted in epithelial dilation and increased mesenchyme (Taniguchi et al. 2007). In contrast, overexpression of Spry2 suppressed branching and occasionally led to the agenesis of entire lung lobes (Mailleux et al. 2001).

The expression pattern of Fgflo is dynamic and spatially restricted to distal mesenchyme by $\mathrm{SHH}$ signaling (Bellusci et al. 1997; Pepicelli et al. 1998; Lebeche et al. 1999). SHH also promotes Wnt2a expression in distal 
mesenchyme, and Wnt2a promotes mesenchymal differentiation and Fgf10 expression (Goss et al. 2011). FGF10/ FGFR2b signaling is, in turn, required to maintain Shh expression (Fig. 4B) (Abler et al. 2009). In distal mesenchyme, RA negatively regulates Fgf10 expression and RA must be down-regulated distally for normal branching (Fig. 3C) (Malpel et al. 2000). Noncanonical Wnt signaling also regulates epithelial branching. Embryos that lack Wnt5a (Wnt5a $a^{-/-}$) have increased branching and increased expression of FgflO, Bmp4, and Shh, whereas embryos that overexpress Wnt5a have reduced epithelial branching (Fig. 4B) (Li et al. 2002, 2005).

\subsubsection{Regulation of Cell Shape and Polarity Is Necessary for Epithelial Morphogenesis}

Initiation of bud formation requires changes in cell shape, polarity, and cell-cell interactions. Several factors have been identified that regulate cell shape, polarity, and adhesion. FGF10 signaling to distal epithelium activates PI3K/ Akt to induce expression of the Ets transcription factor Elf5 (Metzger et al. 2007). Although overexpression of Elf5 disrupts branching and suppresses distal epithelial differentiation (Metzger et al. 2008a), it is not known whether Elf5 is necessary for epithelial morphogenesis. The mitogen-activated protein (MAP) kinase, p38 $\alpha$, is localized specifically in the distal endoderm and inhibition of p38 $\alpha$ impairs epithelial budding. p38 $\alpha$ can be activated in response to FGF10 and it functions to inhibit E-cadherin expression. Down-regulation of E-cadherin is necessary for budding, and budding can be in-hibited by overexpression of Ecadherin (Liu et al. 2008). Although inhibition of Erks (expressed throughout lung epithelium) also prevented FGF10-induced budding, the mechanism is independent of regulation of E-cadherin, and likely due to the effects of Erk signaling on cell shape and spindle polarity (Liu et al. 2008; Tang et al. 2011). The protein tyrosine phosphatase and transcriptional coactivator, eyes absent (Eya1) and the homeobox gene, Sixl, are also expressed in distal epithelium (El-Hashash et al. 2011a,b). Embryos lacking Eya1 or Sixl have severely hypoplastic lungs. However, during the mid to late pseudoglandular stage, they show increased mesenchymal proliferation and decreased epithelial proliferation. In the epithelium, one function of Eyal is to regulate cell polarity and the plane of cell division during branching (El-Hashash et al. 2011c).

Several additional factors have been identified that function to fine-tune the branching process. These include netrin 1 and netrin 4, Celsr1, and Wnt5a. The guidance molecules, netrin 1 and netrin 4, are expressed in nonbranching (proximal) endoderm and are excluded from the distal tip. The netrin receptor, DCC, is expressed in the basal-lateral membrane of proximal endoderm and on the apical surface of distal tip epithelium. The netrin coreceptor, Unc5b, is also expressed in distal epithelium. Netrin signaling inhibits FGF10-induced pErk, effectively preventing ectopic budding and fine-tuning the shape of the bud (Liu et al. 2004). Loss-of-function mutations in the planar cell polarity genes, Celsr1 and Vangl2, result in reduced lung epithelial budding and abnormal epithelial cell morphology (Yates et al. 2010). Celsr 1 colocalizes with laminin in regions where bud growth is constrained and thus may be important for bud bifarcation or stabilization of the cleft between branches (Yates et al. 2010). Lung epithelium, in Celsr 1 and Vangl2 mutants, has an impaired response to FGF10, resulting in lung hypoplasia.

\subsection{Molecular Mechanisms Regulating Mesenchymal Growth and Differentiation}

The mesenchymal compartment of the developing lung gives rise to the lung vasculature (endothelial cells, pericytes, and vascular smooth muscle), bronchial smooth muscle, myofibroblasts, and interstitial fibroblasts. Lung mesenchyme is also essential for regulating the patterning and extent of epithelial branching and is a key determinant in regulating the overall size and shape of the lung. Proximo-distal patterning of the lung may be, in part, intrinsic to lung mesenchyme because mesenchymal protrusions occur even in the absence of FGF10/FGFR2b signaling and epithelial branching (Abler et al. 2009).

Lung mesenchyme is not homogeneous, and histological criteria and molecular markers subdivide it into submesothelial (SMM) and subepithelial (SEM) domains (White et al. 2006). Submesothelial mesenchyme is marked by expression of $W n t 2 a$, and subepithelial mesenchyme expresses Noggin (Fig. 5A,B) (Levay-Young and Navre 1992; Bellusci et al. 1996; Weaver et al. 2003; Yin et al. 2008). Progenitor cells for bronchial smooth muscle and interstitial fibroblasts are located in the distal tip submesothelial mesenchyme (Mailleux et al. 2005), whereas vascular endothelial cells are first observed between submesothelial and subepithelial zones (Fig. 5C,D) (Partanen et al. 1996; Hall et al. 2000; White et al. 2006, 2007). Neuronal components of the lung are derived from migrating neural crest cells that begin to populate foregut mesenchyme before formation of the lung bud and continue to enter the lung during early pseudoglandular development (Tollet et al. 2001).

\subsubsection{FGF and Wnt Signals Regulate Lung Mesenchyme Development}

Fgf 9 is a critical regulator of lung mesenchyme. Fgf 9 is expressed in the mesothelium and epithelium (Fig. 4) 
D.M. Ornitz and Y. Yin

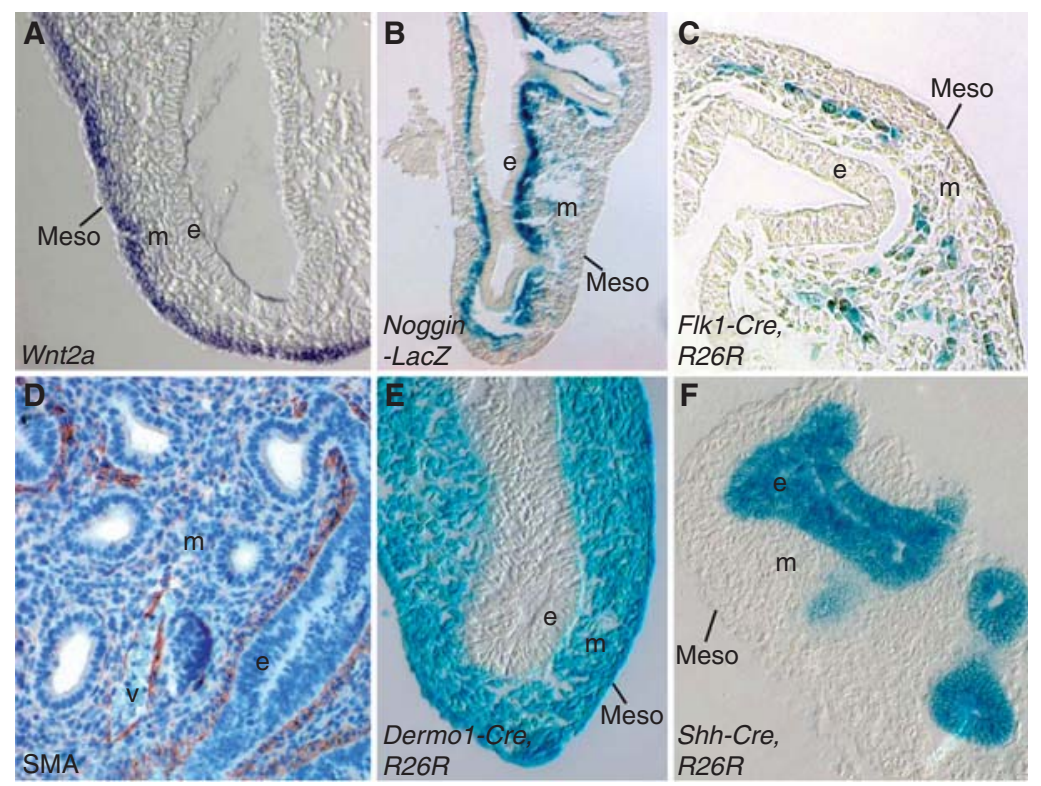

Figure 5. Molecular markers expressed in pseudoglandular stage lung mesenchyme. (A) Wnt2a expression in submesothelial mesenchyme. (B) Noggin-LacZ expression in subepithelial mesenchyme. (C) Endothelial lineage marked by Flk1-Cre activation of the R26R reporter gene. (D) Smooth muscle actin (Sma) expression in peribronchiolar and perivascular tissue. (E) Mesodermal and mesothelial lineage marked by Dermo1-Cre activation of the R26R reporter gene. $(F)$ Epithelial lineages marked by Shh-Cre activation of the R26R reporter gene. e, epithelium; $\mathrm{m}$, mesenchyme; meso, mesothelium; v, blood vessel.

(Colvin et al. 1999; del Moral et al. 2006a). In the absence of FGF9 $\left(\mathrm{Fgf9}^{-/-}\right)$, lungs are severely hypoplastic, resulting in perinatal death (Colvin et al. 2001; White et al. 2006). Fgf $9^{-1-}$ embryos show decreased mesenchymal proliferation and decreased epithelial branching.

FGF9 primarily signals to mesenchymal FGF receptors (FGFRs) 1 and 2, but also can activate epithelial FGFR signaling (del Moral et al. 2006a; White et al. 2006, 2007; Yin et al. 2008). During the early (E12.5) pseudoglandular stage, mesenchymal FGF signaling and Wnt $/ \beta$-catenin signaling function to positively reinforce each other (Fig. 4C) (Yin et al. 2008, 2011). Mesenchymal FGF signaling is required for expression of $W n t 2 a$, and mesenchymal Wnt / $\beta$-catenin signaling is required to sustain expression of FGFRs 1 and 2 (De Langhe et al. 2008; Yin et al. 2008, 2009). Consistent with this feed-forward signaling loop, inactivation of mesenchymal $\beta$-catenin also results in decreased mesenchymal proliferation and decreased cyclinD1 expression (Yin et al. 2008).

Inactivation of a conditional allele of $F g f 9$ (Lin et al. 2006) in mesothelium (Dermo1-Cre ${ }^{6}$ ) (Figs. 4C and 5E) showed that mesothelial-derived FGF9 is primarily responsible for regulating mesenchymal proliferation and has

${ }^{6}$ The Dermo1-Cre knockin allele drives Cre recombinase expression in mesenchyme (Yu et al. 2003). little influence on epithelial branching. In contrast, inactivation of Fgf9 in epithelium (Shh-Cre) showed that epithelial-derived $\mathrm{Fgfg}$ influences epithelial branching and epithelial proliferation but has little effect on mesenchymal proliferation (Figs. 4C and 5F) (Yin et al. 2011). In Fgf9 ${ }^{-1-}$ lung or in lungs in which mesenchymal $\beta$-catenin has been conditionally inactivated (Dermo1-Cre), lung mesenchyme cannot be rescued by addition of exogenous FGF9 (Yin et al. 2008, 2011). This loss of responsiveness of mesenchyme is attributable to degeneration of feed-forward FGFWnt/ $\beta$-catenin signaling and loss of mesenchymal FGFR expression. $\mathrm{Fgf9}^{-}{ }^{-}$mesenchyme can, however, be rescued if FGF9 is added along with agents that stabilize $\beta$-catenin ( $\mathrm{LiCl}, \mathrm{BIO}$ ) (Yin et al. 2011). In addition to mesothelial and epithelial Fgf9 and mesenchymal Wnt2a, Wnt7b (expressed in developing epithelium) is also required for lung development where it activates mesenchymal and epithelial Wnt/ $\beta$-catenin signaling (Rajagopal et al. 2008; Yin et al. 2011). Examination of mesenchymal growth in explant cultures shows a small response to activation of $\mathrm{Wnt} / \beta$ catenin signaling and a large response to FGF9, indicating that FGF9 signaling is the dominant pathway regulating mesenchymal proliferation and suggesting that $\mathrm{Wnt} / \beta$ catenin signaling primarily functions as a permissive factor for FGF9/FGFR1c/2c signaling (Yin et al. 2011).

Also observed in lungs lacking mesenchymal FGF or Wnt/ $\beta$-catenin signaling was decreased epithelial 
proliferation, which occurred later in development than the decreased mesenchymal proliferation. This suggests that loss of mesenchymal FGF or $\beta$-catenin signaling has a primary effect on mesenchymal proliferation and a secondary (delayed) effect on epithelial proliferation. A potential mechanism by which mesenchymal FGF-Wnt/ $\beta$-catenin signaling could regulate epithelial proliferation is through modulation of BMP4 signaling. Two endogenous inhibitors of BMP4 signaling, Grem1 and Noggin, are expressed in pseudoglandular stage lung mesenchyme (Weaver et al. 1999, 2003; Shi et al. 2001). In lung explant cultures, FGF9 beads suppress Noggin expression (Weaver et al. 2003), and in embryonic lung that lacks mesenchymal FGF or Wnt $/ \beta$ catenin signaling, Noggin expression is up-regulated (Yi et al. 2009, 2011). Treatment of lung mesenchymal explants with SHH also leads to increased Noggin (Weaver et al. 2003).

\subsubsection{Smooth Muscle Differentiation Is Regulated by Factors Intrinsic and Extrinsic to Lung Mesenchyme}

Wnt signaling regulates the progenitor cells that give rise to bronchial (Wnt2a, Wnt7b) and vascular (Wnt7b) smooth muscle (Shu et al. 2002; Wang et al. 2005; Cohen et al. 2009; Goss et al. 2011). Consistent with the role of Wnt ligands in smooth muscle development, inactivation of mesenchymal Wnt $/ \beta$-catenin signaling impairs the development of progenitor cells that give rise to bronchial and vascular smooth muscle (De Langhe et al. 2008; Cohen et al. 2009). Expansion of bronchial smooth muscle progenitors is likely mediated by submesothelial Wnt2a (Goss et al. 2011), whereas Wnt7b signaling through Fzd1 preferentially regulates differentiation of vascular smooth muscle (Shu et al. 2002; Wang et al. 2005). Wnt signaling may promote smooth muscle differentiation by up-regulating the expression of $P d g f r \beta$ (Cohen et al. 2009; Goss et al. 2011), which is required for normal smooth muscle development. In addition, FGF9 signaling inhibits and BMP4 signaling promotes bronchial smooth muscle differentiation (Weaver et al. 2003; Mailleux et al. 2005; White et al. 2006; Yi et al. 2009), and SHH signaling is important for the formation of bronchial and tracheal (but not vascular) smooth muscle, and possibly for the survival of vascular smooth muscle (Pepicelli et al. 1998; Li et al. 2004; Miller et al. 2004; van Tuyl et al. 2007).

\subsubsection{Coordination of Vascular and Epithelial Development}

Lung vascular development occurs concurrently with epithelial branching morphogenesis (Gebb and Shannon 2000; Schachtner et al. 2000; Parera et al. 2005). During early pseudoglandular development, the primitive capillary plexus expands by angiogenesis (sprouting from preexisting vessels) and is maintained at a constant distance from the epithelial ducts (deMello et al. 1997; Hall et al. 2000). VegfA is essential for vascular development, and vascular development is required for normal epithelial branching (Lazarus et al. 2011). In explant culture, VegfA is sufficient to stimulate neoangiogenesis (Healy et al. 2000), to increase mesenchymal Flk1 (Vegfr2)-positive cells and, by poorly understood mechanisms, to promote epithelial branching morphogenesis (Del Moral et al. 2006b; Lazarus et al. 2011). Inhibition of VegfA (overexpression of secreted Vegfr 1) reduces vascular development and impairs epithelial development, resulting in malrotation of dorsoventral branches and inhibition of orthogonal bifurcations (Gerber et al. 1999; Ng et al. 2001; Zhao et al. 2005; Lazarus et al. 2011). In the absence of blood vessels, Fgf10 expression domains were expanded and Shh and Sprouty2 levels were increased, suggesting that the vasculature actually plays a key role in coordinating epithelial morphogenesis.

During early pseudoglandular stage development, Veg$f A$ is expressed throughout lung mesenchyme, and endothelial cells are localized between submesothelial and subepithelial domains (Fig. 5C) (White et al. 2007). Slightly later, the capillary plexus is drawn toward the epithelial tubes coincident with increased expression of epithelial VegfA (Healy et al. 2000; White et al. 2007). During the saccular stage (E18.5), VegfA expression becomes restricted to a subpopulation of cells that line the saccular walls, and VegfA protein is localized in distal lung epithelial cells where it serves as a chemotactic signal for the vasculature (Healy et al. 2000; White et al. 2007; Ahlbrecht et al. 2008).

In addition to VegfA, FGF9, SHH, and Wnt/ $\beta$-catenin signaling regulate vasculogenesis. FGF9 suppresses vasculogenesis but does not directly affect endothelial cell development (del Moral et al. 2006a). Rather, FGF9 indirectly regulates capillary plexus density through regulation of mesenchymal (but not epithelial) VegfA expression (White et al. 2007). SHH is required for normal vasculogenesis and endothelial cell survival and functions independent of FGF9 (Miller et al. 2004; van Tuyl et al. 2007; White et al. 2007). Wnt7b is required for formation of the smooth muscle component of the major pulmonary vessels (Shu et al. 2002).

\subsection{MicroRNAs Regulate Epithelial and Mesenchymal Gene Expression to Fine-Tune Lung Development}

MicroRNAs regulate mRNA stability and translation and have important roles in fine-tuning development. Dicer1, and other enzymes required to process microRNAs, are 
expressed in pseudoglandular stage distal mesenchyme and epithelium ( $\mathrm{Lu}$ et al. 2005). Inactivation of a conditional allele of Dicer1 throughout lung epithelium (Shh-Cre) resulted in the formation of large epithelial pouches, reduced epithelial branching, and mesenchymal thickening (Harris et al. 2006), phenotypes that were first evident at E12.5. Later in development (E13.5), increased epithelial cell death was observed. Examination of the expression patterns of genes that could directly affect epithelial morphogenesis identified increased expression of mesenchymal Fgf10 (Harris et al. 2006). However, because Dicer1 was specifically inactivated in epithelium, it is likely that epithelial microRNAs regulate an epithelial gene that encodes a factor that signals to mesenchyme that regulates $\mathrm{FgflO}$ expression. The two most likely candidate genes are Fgf9 and Shh.

Many microRNAs are differentially expressed during lung development (Williams et al. 2007; Bhaskaran et al. 2009; Carraro et al. 2009; Dong et al. 2010). Several of these microRNAs have been identified as important for lung development and the pathogenesis of lung cancer and other lung diseases. miR-127 is expressed at highest levels in saccular stage lung development. Overexpression of $m i R$ 127 in explant cultures of pseudoglandular stage lung caused decreased branching and enlarged terminal buds (Bhaskaran et al. 2009). miR-17 and its paralogs, miR20a and miR-106b, are expressed in epithelium and mesenchyme during pseudoglandular stage development. Inhibition of these three miRNAs in epithelial explants impaired FGF10-induced budding. Mapk14 and Stat3 are direct targets of miR-17 and are thought to regulate expression of E-cadherin (Carraro et al. 2009). Transgenic overexpression of the miR-17-92 cluster (miR-17-5p, -17-3p, $-18 a,-19 a,-19 b,-20 a$, and $-92 a)$ under the control of Sftpc regulatory elements enhances the proliferation and selfrenewal of embryonic lung epithelial progenitor cells and delays their differentiation (Lu et al. 2007, 2008). Mouse embryos lacking the miR-17-92 cluster showed severely hypoplastic lungs at E18.5, but without specific defects in branching morphogenesis (Ventura et al. 2008). The miR302/367 cluster is a direct target of Gata6 in early pseudoglandular stage airway epithelium. After E12.5, miR302/ 367 expression declines. Inactivation of miR302/367 activity results in decreased epithelial proliferation and enhanced differentiation (Tian et al. 2011). miR302/367 functions to repress expression of the tumor suppressor, $\mathrm{Rbl2}$, and the cell-cycle regulator, Cdkn1a, as well as the polarity factors, Tiam1 and Lis1 (Tian et al. 2011). miR1792 also targets $R b l 2$ (Lu et al. 2007). These microRNAs thus function to coordinate endodermal proliferation, differentiation, and apical-basal polarity (Lu et al. 2008; Tian et al. 2011).

\section{REGULATION OF LUNG SIZE AND SHAPE}

Mechanisms that regulate the size and the shape of the lung are a particularly intriguing problem. As discussed above, there are multiple genetically encoded factors that determine the overall lobulation pattern of the lung and that even specify the stereotypic location and orientation of the first several generations of branches. However, the structure of the lung is sufficiently complex, such that additional extrinsic factors must also modulate its development. For example, throughout the later stages of embryonic development and beyond, the shape of the lung conforms precisely to that of the thoracic cavity, whereas lung explants grown in vitro take on a more rounded shape. Thus, constraints imposed by the thoracic cavity must act to shape the lung.

\subsection{Extrinsic Factors that Regulate Lung Size}

Changes in intrathoracic pressure have been considered as a mechanism that could regulate growth of the lung and even sculpt the lung to the contour of the thoracic cavity. During development, fetal respiratory movements and intratracheal fluid production produce pressure changes within and around the developing lung. Fetal respiratory movements have been detected as early as E14.5 in the mouse (Abadie et al. 2000) and at $10 \mathrm{wk}$ gestation in human (de Vries et al. 1986).

The importance of fetal mechanical forces on lung development has been shown by tracheal occlusion, which increases intratracheal pressure, or in mice congenitally lacking muscle activity, which prevents fetal breathing movements. Increased intratracheal pressure resulted in increased branching, proliferation, and branch elongation. These effects are dependent on intact FGF10/FGFR2b signaling (Unbekandt et al. 2008). Mice lacking the myogenic factors MyoD and/or Myf5 had hypoplastic lungs, decreased epithelial proliferation, increased apoptosis, and failure to fully differentiate type I and type II pneumocytes (Liu and Post 2000; Inanlou and Kablar, 2005a,b; BagumaNibasheka et al. 2007).

Mechanical stretch stimulates lung epithelial cell proliferation and promotes cell maturation (Liu and Post 2000). One mechanism is through the regulation of Rho activity. Rho, a GTPase that promotes the phosphorylation of myosin light chain kinase (MLCK), activates the Rhoassociated kinase (ROCK), inhibits MLC phosphatase, and stimulates cytoskeletal contractility (Olson 2004; Moore et al. 2005). Inhibition of the Rho/ROCK signaling pathway in lung explant cultures decreased branching without affecting cell proliferation (Moore et al. 2005).

Congenital space occupying lesions in the chest, such as congenital diaphragmatic hernia and cystic adenomatoid 
malformation of the lung, can severely limit lung growth (Kinane 2007; Robinson and Fitzgerald 2007). Limits imposed by the chest wall and diaphragm also limit lung size. However, in rodents and young children, partial pneumonectomy results in compensatory growth of the contralateral lung to restore respiratory capacity (McBride et al. 1980). Therefore, physical and humeral factors can overcome intrinsic genetic programs. Additionally, environmental factors, imposed by altitude or pollution, can also affect lung development and function (Dashdendev et al. 2011).

\section{PERSPECTIVES}

The origins of chronic lung disease often begin during embryonic development or early in life. Unraveling the complex mechanisms that regulate lung development is therefore essential for understanding the pathogenesis of developmental, genetic, and acquired lung disease. Progress is being made on elucidating the developmental mechanisms that regulate differentiation of the specific cell types that populate the lung. However, other areas of lung development are less well understood. For example, it is not known how the growth of progenitor cells and their differentiated progeny are coordinated to regulate the overall size and shape of the lung. These mechanisms are likely to involve biomechanical factors, such as differential pressure and stretch of lung epithelium and mesothelium; physical constraints imposed by the chest cavity; humoral factors that communicate the oxygen requirements of the organism to the developing lung (and chest cavity); and intrinsic genetic factors that have evolved to optimize lung architecture (branching pattern and alveolar surface area) for efficient physiological function.

To design and implement therapeutic strategies to induce lung growth and regeneration will require a comprehensive understanding of the identity of progenitor cells within epithelial and mesenchymal compartments of both the embryonic and postnatal lung. Manipulation of the growth and differentiation properties of lung progenitor cells will be important for both in vivo and in vitro therapeutic approaches to lung repair and for understanding homeostatic mechanisms that are essential to replace damaged cells. To repopulate damaged lung tissue in vivo or repopulate lung matrix scaffolds in vitro will require large numbers of cells. This will require understanding the mechanisms that regulate growth and differentiation of epithelial and mesenchymal progenitors into the specific cell types that populate the mature lung and devising methods to grow and differentiate these cells in vitro. The ultimate goal of lung developmental studies is to improve diagnosis of inherited and acquired disease and to learn how to therapeutically manipulate developmental programs to reestablish homeostasis, regenerate damaged or deficient cell populations, and eventually to generate functional replacement lung tissue in vitro for transplantation in vivo.

\section{ACKNOWLEDGMENTS}

We thank David Warburton for his constructive comments. This work was funded by a grant from the March of Dimes Foundation, the Washington University Department of Developmental Biology, and a gift from Edward and Linda Ornitz.

\section{REFERENCES}

* Reference is also in this collection.

Abadie V, Champagnat J, Fortin G. 2000. Branchiomotor activities in mouse embryo. Neuroreport 11: 141-145.

Abler LL, Mansour SL, Sun X. 2009. Conditional gene inactivation reveals roles for Fgf10 and Fgfr2 in establishing a normal pattern of epithelial branching in the mouse lung. Dev Dyn 238: 1999-2013.

Ahlbrecht K, Schmitz J, Seay U, Schwarz C, Mittnacht-Kraus R, Gaumann A, Haberberger RV, Herold S, Breier G, Grimminger F, et al. 2008. Spatiotemporal expression of flk-1 in pulmonary epithelial cells during lung development. Am J Respir Cell Mol Biol 39: 163-170.

Aubin J, Lemieux M, Tremblay M, Berard J, Jeannotte L. 1997. Early postnatal lethality in Hoxa-5 mutant mice is attributable to respiratory tract defects. Dev Biol 192: 432-445.

Baguma-Nibasheka M, Angka HE, Inanlou MR, Kablar B. 2007. Microarray analysis of $\mathrm{Myf5}^{-/-}: \mathrm{MyoD}^{-/-}$hypoplastic mouse lungs reveals a profile of genes involved in pneumocyte differentiation. Histol Histopathol 22: 483-495.

Balfour FM. 1881. The alimentary canal and its appendages in the Chordata. In A treatise on comparative embryology, pp. 620-643. Macmillan and Co., London.

Bellusci S. 2008. Lung stem cells in the balance. Nat Genet 40: 822-824.

Bellusci S, Henderson R, Winnier G, Oikawa T, Hogan BL. 1996. Evidence from normal expression and targeted misexpression that bone morphogenetic protein (Bmp-4) plays a role in mouse embryonic lung morphogenesis. Development 122: 1693-1702.

Bellusci S, Grindley J, Emoto H, Itoh N, Hogan BL. 1997. Fibroblast growth factor 10 (FGF10) and branching morphogenesis in the embryonic mouse lung. Development 124: 4867-4878.

Bhaskaran M, Wang Y, Zhang H, Weng T, Baviskar P, Guo Y, Gou D, Liu L. 2009. MicroRNA-127 modulates fetal lung development. Physiol Genomics 37: 268-278.

Bogue CW, Lou LJ, Vasavada H, Wilson CM, Jacobs HC. 1996. Expression of Hoxb genes in the developing mouse foregut and lung. Am J Respir Cell Mol Biol 15: 163-171.

Brown E, James K. 2009. The lung primordium an outpouching from the foregut! Evidence-based dogma or myth? J Pediatr Surg 44: 607-615.

Brunet LJ, McMahon JA, McMahon AP, Harland RM. 1998. Noggin, cartilage morphogenesis, and joint formation in the mammalian skeleton. Science 280: 1455-1457.

Cardoso WV. 2000. Lung morphogenesis revisited: Old facts, current ideas. Dev Dyn 219: 121-130.

Cardoso WV, Kotton DN. 2008. Specification and patterning of the respiratory system. In StemBook (ed. The Stem Cell Research Community). StemBook, doi: 10.3824/stembook.1.10.1. 
Cardoso WV, Lu J. 2006. Regulation of early lung morphogenesis: Questions, facts and controversies. Development 133: 1611-1624.

Carraro G, El-Hashash A, Guidolin D, Tiozzo C, Turcatel G, Young BM, De Langhe SP, Bellusci S, Shi W, Parnigotto PP, et al. 2009. miR-17 family of microRNAs controls FGF10-mediated embryonic lung epithelial branching morphogenesis through MAPK14 and STAT3 regulation of E-Cadherin distribution. Dev Biol 333: 238-250.

Cebra-Thomas JA, Bromer J, Gardner R, Lam GK, Sheipe H, Gilbert SF. 2003. T-box gene products are required for mesenchymal induction of epithelial branching in the embryonic mouse lung. Dev Dyn 226: $82-90$.

Chapman DL, Garvey N, Hancock S, Alexiou M, Agulnik SI, GibsonBrown JJ, Cebra-Thomas J, Bollag RJ, Silver LM, Papaioannou VE. 1996. Expression of the T-box family genes, Tbx1-Tbx5, during early mouse development. Dev Dyn 206: 379-390.

Chen F, Desai TJ, Qian J, Niederreither K, Lu J, Cardoso WV. 2007. Inhibition of Tgf $\beta$ signaling by endogenous retinoic acid is essential for primary lung bud induction. Development 134: 2969-2979.

Chen F, Cao Y, Qian J, Shao F, Niederreither K, Cardoso WV. 2010. A retinoic acid-dependent network in the foregut controls formation of the mouse lung primordium. J Clin Invest 120: 2040-2048.

Chuang PT, Kawcak T, McMahon AP. 2003. Feedback control of mammalian Hedgehog signaling by the Hedgehog-binding protein, Hip1, modulates Fgf signaling during branching morphogenesis of the lung. Genes Dev 17: 342-347.

Cohen ED, Ihida-Stansbury K, Lu MM, Panettieri RA, Jones PL, Morrisey EE. 2009. Wnt signaling regulates smooth muscle precursor development in the mouse lung via a tenascin C/PDGFR pathway. J Clin Invest 119: $2538-2549$.

Colvin JS, Feldman B, Nadeau JH, Goldfarb M, Ornitz DM. 1999. Genomic organization and embryonic expression of the mouse fibroblast growth factor 9 gene. Dev Dyn 216: 72-88.

Colvin JS, White A, Pratt SJ, Ornitz DM. 2001. Lung hypoplasia and neonatal death in Fgf9-null mice identify this gene as an essential regulator of lung mesenchyme. Development 128: 2095-2106.

Danesh SM, Villasenor A, Chong D, Soukup C, Cleaver O. 2009. BMP and BMP receptor expression during murine organogenesis. Gene Expr Patterns 9: 255-265.

Dashdendev B, Fukushima LK, Woo MS, Ganbaatar E, Warburton D. 2011. Carbon monoxide pollution and lung function in urban compared with rural Mongolian children. Respirology 16: 653-658.

De Langhe SP, Sala FG, Del Moral PM, Fairbanks TJ, Yamada KM, Warburton D, Burns RC, Bellusci S. 2005. Dickkopf-1 (DKK1) reveals that fibronectin is a major target of Wnt signaling in branching morphogenesis of the mouse embryonic lung. Dev Biol 277: 316-331.

De Langhe SP, Carraro G, Tefft D, Li C, Xu X, Chai Y, Minoo P, Hajihosseini MK, Drouin J, Kaartinen V, et al. 2008. Formation and differentiation of multiple mesenchymal lineages during lung development is regulated by $\beta$-catenin signaling. PLoS ONE 3: e1516.

Del Moral PM, De Langhe SP, Sala FG, Veltmaat JM, Tefft D, Wang K, Warburton D, Bellusci S. 2006a. Differential role of FGF9 on epithelium and mesenchyme in mouse embryonic lung. Dev Biol 293: $77-89$.

Del Moral PM, Sala FG, Tefft D, Shi W, Keshet E, Bellusci S, Warburton D. 2006b. VEGF-A signaling through Flk-1 is a critical facilitator of early embryonic lung epithelial to endothelial crosstalk and branching morphogenesis. Dev Biol 290: 177-188.

deMello DE, Sawyer D, Galvin N, Reid LM. 1997. Early fetal development of lung vasculature. Am J Respir Cell Mol Biol 16: 568-581.

Desai TJ, Malpel S, Flentke GR, Smith SM, Cardoso WV. 2004. Retinoic acid selectively regulates Fgf10 expression and maintains cell identity in the prospective lung field of the developing foregut. Dev Biol 273: $402-415$

Desai TJ, Chen F, Lu J, Qian J, Niederreither K, Dolle P, Chambon P, Cardoso WV. 2006. Distinct roles for retinoic acid receptors $\alpha$ and $\beta$ in early lung morphogenesis. Dev Biol 291: 12-24.
Deutsch GH, Pinar H. 2002. Prenatal lung development. In Chronic obstructive lung diseases (ed. Norbert WM, Voelkel F). PMPH-USA.

de Vries JI, Visser GH, Prechtl HF. 1986. Fetal behaviour in early pregnancy. Eur J Obstet Gynecol Reprod Biol 21: 271-276.

Domyan ET, Sun X. 2011. Patterning and plasticity in development of the respiratory lineage. Dev Dyn 240: 477-485.

Domyan ET, Ferretti E, Throckmorton K, Mishina Y, Nicolis SK, Sun X. 2011. Signaling through BMP receptors promotes respiratory identity in the foregut via repression of Sox2. Development 138: 971-981.

Dong J, Jiang G, Asmann YW, Tomaszek S, Jen J, Kislinger T, Wigle DA. 2010. MicroRNA networks in mouse lung organogenesis. PLoS ONE 5: e10854.

Dubreuil G, Lacoste A, Raymond R. 1936. Observations sur le developpement du poumon humain. Bull Histol Appliq Physiol Pathol 13: $235-245$.

Eblaghie MC, Reedy M, Oliver T, Mishina Y, Hogan BL. 2006. Evidence that autocrine signaling through Bmprla regulates the proliferation, survival and morphogenetic behavior of distal lung epithelial cells. Dev Biol 291: 67-82.

El-Hashash AH, Al Alam D, Turcatel G, Bellusci S, Warburton D. 2011a. Eyes absent 1 (Eya1) is a critical coordinator of epithelial, mesenchymal and vascular morphogenesis in the mammalian lung. Dev Biol 350: $112-126$.

El-Hashash AH, Al Alam D, Turcatel G, Rogers O, Li S, Bellusci S, Warburton D. 2011b. Six1 transcription factor is critical for coordination of epithelial, mesenchymal and vascular morphogenesis in the mammalian lung. Dev Biol 353: 242-258.

El-Hashash AH, Turcatel G, Al Alam D, Buckley S, Tokumitsu H, Bellusci S, Warburton D. 2011c. Eyal controls cell polarity, spindle orientation, cell fate and Notch signaling in distal embryonic lung epithelium. Development 138: 1395-1407.

Gebb SA, Shannon JM. 2000. Tissue interactions mediate early events in pulmonary vasculogenesis. Dev Dyn 217: 159-169.

Gerber HP, Hillan KJ, Ryan AM, Kowalski J, Keller GA, Rangell L, Wright BD, Radtke F, Aguet M, Ferrara N. 1999. VEGF is required for growth and survival in neonatal mice. Development 126: 1149-1159.

Giangreco A, Reynolds SD, Stripp BR. 2002. Terminal bronchioles harbor a unique airway stem cell population that localizes to the bronchoalveolar duct junction. Am J Pathol 161: 173-182.

Giangreco A, Arwert EN, Rosewell IR, Snyder J, Watt FM, Stripp BR. 2009. Stem cells are dispensable for lung homeostasis but restore airways after injury. Proc Natl Acad Sci 106: 9286-9291.

Gibson-Brown JJ, I Agulnik S, Silver LM, Papaioannou VE. 1998. Expression of T-box genes Tbx2-Tbx5 during chick organogenesis. Mech Dev 74: 165-169.

Goss AM, Tian Y, Tsukiyama T, Cohen ED, Zhou D, Lu MM, Yamaguchi TP, Morrisey EE. 2009. Wnt $2 / 2 \mathrm{~b}$ and $\beta$-catenin signaling are necessary and sufficient to specify lung progenitors in the foregut. Dev Cell 17: 290-298.

Goss AM, Tian Y, Cheng L, Yang J, Zhou D, Cohen ED, Morrisey EE. 2011. Wnt2 signaling is necessary and sufficient to activate the airway smooth muscle program in the lung by regulating myocardin/Mrtf-B and Fgf10 expression. Dev Biol 356: 541-552.

Gray H. 2000. Anatomy of the human body (ed. Lewis WH), p. 1396. Lea \& Febiger, Philadelphia.

Hall SM, Hislop AA, Pierce CM, Haworth SG. 2000. Prenatal origins of human intrapulmonary arteries: Formation and smooth muscle maturation. Am J Respir Cell Mol Biol 23: 194-203.

Harfe BD, Scherz PJ, Nissim S, Tian H, McMahon AP, Tabin CJ. 2004. Evidence for an expansion-based temporal Shh gradient in specifying vertebrate digit identities. Cell 118: 517-528.

Harpole DEJ, Aloia TA. 2005. Embryology of the lungs. In General thoracic surgery (ed. Shields TW, et al.). Lippincott Williams \& Wilkins, Philadelphia.

Harris KS, Zhang Z, McManus MT, Harfe BD, Sun X. 2006. Dicer function is essential for lung epithelium morphogenesis. Proc Natl Acad Sci 103: $2208-2213$. 
Harris-Johnson KS, Domyan ET, Vezina CM, Sun X. 2009. $\beta$-Catenin promotes respiratory progenitor identity in mouse foregut. Proc Natl Acad Sci 106: 16287-16292.

Hashimoto S, Nakano H, Singh G, Katyal S. 2002. Expression of Spred and Sprouty in developing rat lung. Gene Expr Patterns 2: 347-353.

Healy AM, Morgenthau L, Zhu X, Farber HW, Cardoso WV. 2000. VEGF is deposited in the subepithelial matrix at the leading edge of branching airways and stimulates neovascularization in the murine embryonic lung. Dev Dyn 219: 341-352.

Hilfer SR, Rayner RM, Brown JW. 1985. Mesenchymal control of branching pattern in the fetal mouse lung. Tissue Cell 17: 523-538.

Hyatt BA, Shangguan X, Shannon JM. 2004. FGF-10 induces SP-C and Bmp4 and regulates proximal-distal patterning in embryonic tracheal epithelium. Am J Physiol Lung Cell Mol Physiol 287: L1116-L1126.

Inanlou MR, Kablar B. 2005a. Abnormal development of the intercostal muscles and the rib cage in Myf5 $5^{-/-}$embryos leads to pulmonary hypoplasia. Dev Dyn 232: 43-54.

Inanlou MR, Kablar B. 2005b. Contractile activity of skeletal musculature involved in breathing is essential for normal lung cell differentiation, as revealed in Myf5 $5^{-/-}: \mathrm{MyoD}^{-/-}$embryos. Dev Dyn 233: 772-782.

Jang CW, Gao L, Dickinson ME, Behringer RR. 2010. Bmp4-directed nuclear cyan fluorescent protein provides a tool for live imaging and reveals cellular resolution of Bmp4 expression patterns during embryogenesis. Int J Dev Biol 54: 931-938.

Jeffrey PK. 1998. The development of large and small airways. Am J Respir Crit Care Med 157: S174-S180.

Joshi S, Kotecha S. 2007. Lung growth and development. Early Hum Dev 83: 789-794.

Kaufman MH. 1992. The atlas of mouse development. Harcourt Brace \& Company, London.

Kim CF, Jackson EL, Woolfenden AE, Lawrence S, Babar I, Vogel S, Crowley D, Bronson RT, Jacks T. 2005. Identification of bronchioalveolar stem cells in normal lung and lung cancer. Cell 121: 823-835.

Kinane TB. 2007. Lung development and implications for hypoplasia found in congenital diaphragmatic hernia. Am J Med Genet C Semin Med Genet 145: 117-124.

Kitamura K, Miura H, Miyagawa-Tomita S, Yanazawa M, Katoh-Fukui Y, Suzuki R, Ohuchi H, Suehiro A, Motegi Y, Nakahara Y, et al. 1999. Mouse Pitx2 deficiency leads to anomalies of the ventral body wall, heart, extra- and periocular mesoderm and right pulmonary isomerism. Development 126: 5749-5758.

Krumlauf R, Holland PW, McVey JH, Hogan BL. 1987. Developmental and spatial patterns of expression of the mouse homeobox gene, Hox 2.1. Development 99: 603-617.

Lako M, Strachan T, Bullen P, Wilson DI, Robson SC, Lindsay S. 1998. Isolation, characterisation and embryonic expression of WNT11, a gene which maps to 11q13.5 and has possible roles in the development of skeleton, kidney and lung. Gene 219: 101-110.

Lazarus A, Del-Moral PM, Ilovich O, Mishani E, Warburton D, Keshet E. 2011. A perfusion-independent role of blood vessels in determining branching stereotypy of lung airways. Development 138: 2359-2368.

Lazzaro D, Price M, de Felice M, Di Lauro R. 1991. The transcription factor TTF-1 is expressed at the onset of thyroid and lung mor-phogenesis and in restricted regions of the foetal brain. Development 113: $1093-1104$.

Lebeche D, Malpel S, Cardoso WV. 1999. Fibroblast growth factor interactions in the developing lung. Mech Dev 86: 125-136.

Levay-Young BK, Navre M. 1992. Growth and developmental regulation of wnt-2 (irp) gene in mesenchymal cells of fetal lung. Am J Physiol 262: L672-L683.

Li CG, Xiao J, Hormi K, Borok Z, Minoo P. 2002. Wnt5a participates in distal lung morphogenesis. Dev Biol 248: 68-81.

Li Y, Zhang H, Choi SC, Litingtung Y, Chiang C. 2004. Sonic hedgehog signaling regulates Gli3 processing, mesenchymal proliferation, and differentiation during mouse lung organogenesis. Dev Biol 270: $214-231$
Li C, Hu L, Xiao J, Chen H, Li JT, Bellusci S, Delanghe S, Minoo P. 2005. Wnt5a regulates Shh and Fgf10 signaling during lung development. Dev Biol 287: 86-97.

Li Y, Gordon J, Manley NR, Litingtung Y, Chiang C. 2008. Bmp4 is required for tracheal formation: A novel mouse model for tracheal agenesis. Dev Biol 322: 145-155.

Lin Y, Liu G, Wang F. 2006. Generation of an Fgf9 conditional null allele. Genesis 44: 150-154.

Litingtung Y, Lei L, Westphal H, Chiang C. 1998. Sonic hedgehog is essential to foregut development. Nat Genet 20: 58-61.

Liu M, Post M. 2000. Invited review: Mechanochemical signal transduction in the fetal lung. J Appl Physiol 89: 2078-2084.

Liu Y, Stein E, Oliver T, Li Y, Brunken WJ, Koch M, Tessier-Lavigne M, Hogan BL. 2004. Novel role for Netrins in regulating epithelial behavior during lung branching morphogenesis. Curr Biol 14: 897-905.

Liu Y, Martinez L, Ebine K, Abe MK. 2008. Role for mitogen-activated protein kinase p38 $\alpha$ in lung epithelial branching morphogenesis. Dev Biol 314: 224-235.

Lu J, Qian J, Chen F, Tang X, Li C, Cardoso WV. 2005. Differential expression of components of the microRNA machinery during mouse organogenesis. Biochem Biophys Res Commun 334: 319-323.

Lu Y, Thomson JM, Wong HY, Hammond SM, Hogan BL. 2007. Transgenic over-expression of the microRNA miR-17-92 cluster promotes proliferation and inhibits differentiation of lung epithelial progenitor cells. Dev Biol 310: 442-453.

Lu Y, Okubo T, Rawlins E, Hogan BL. 2008. Epithelial progenitor cells of the embryonic lung and the role of microRNAs in their proliferation. Proc Am Thorac Soc 5: 300-304.

Maeda Y, Dave V, Whitsett JA. 2007. Transcriptional control of lung morphogenesis. Physiol Rev 87: 219-244.

Mailleux AA, Tefft D, Ndiaye D, Itoh N, Thiery JP, Warburton D, Bellusci S. 2001. Evidence that SPROUTY2 functions as an inhibitor of mouse embryonic lung growth and morphogenesis. Mech Dev 102: 81-94.

Mailleux AA, Kelly R, Veltmaat JM, De Langhe SP, Zaffran S, Thiery JP, Bellusci S. 2005. Fgf10 expression identifies parabronchial smooth muscle cell progenitors and is required for their entry into the smooth muscle cell lineage. Development 132: 2157-2166.

Malpel S, Mendelsohn C, Cardoso WV. 2000. Regulation of retinoic acid signaling during lung morphogenesis. Development 127: 3057-3067.

McBride JT, Wohl ME, Strieder DJ, Jackson AC, Morton JR, Zwerdling RG, Griscom NT, Treves S, Williams AJ, Schuster S. 1980. Lung growth and airway function after lobectomy in infancy for congenital lobar emphysema. J Clin Invest 66: 962-970.

McMahon JA, Takada S, Zimmerman LB, Fan CM, Harland RM, McMahon AP. 1998. Noggin-mediated antagonism of BMP signaling is required for growth and patterning of the neural tube and somite. Genes Dev 12: 1438-1452.

Merei JM, Farmer P, Hasthorpe S, Qi BQ, Beasley SW, Myers NA, Hutson JM. 1997. Timing and embryology of esophageal atresia and tracheoesophageal fistula. Anat Rec 249: 240-248.

Metzger DE, Xu Y, Shannon JM. 2007. Elf5 is an epithelium-specific, fibroblast growth factor-sensitive transcription factor in the embryonic lung. Dev Dyn 236: 1175-1192.

Metzger DE, Stahlman MT, Shannon JM. 2008a. Misexpression of ELF5 disrupts lung branching and inhibits epithelial differentiation. Dev Biol 320: 149-160.

Metzger RJ, Klein OD, Martin GR, Krasnow MA. 2008b. The branching programme of mouse lung development. Nature 453: 745-750.

Michos O, Panman L, Vintersten K, Beier K, Zeller R, Zuniga A. 2004. Gremlin-mediated BMP antagonism induces the epithelial-mesenchymal feedback signaling controlling metanephric kidney and limb organogenesis. Development 131: 3401-3410.

Miller LA, Wert SE, Clark JC, Xu Y, Perl AK, Whitsett JA. 2004. Role of Sonic hedgehog in patterning of tracheal-bronchial cartilage and the peripheral lung. Dev Dyn 231: 57-71.

Min H, Danilenko DM, Scully SA, Bolon B, Ring BD, Tarpley JE, DeRose M, Simonet WS. 1998. Fgf-10 is required for both limb and lung 
development and exhibits striking functional similarity to Drosophila branchless. Genes Dev 12: 3156-3161.

Minoo P, Su G, Drum H, Bringas P, Kimura S. 1999. Defects in tracheoesophageal and lung morphogenesis in Nkx2.1 $1^{-1-}$ mouse embryos. Dev Biol 209: 60-71.

Monkley SJ, Delaney SJ, Pennisi DJ, Christiansen JH, Wainwright BJ. 1996. Targeted disruption of the Wnt2 gene results in placentation defects. Development 122: 3343-3353.

Moore KA, Polte T, Huang S, Shi B, Alsberg E, Sunday ME, Ingber DE. 2005. Control of basement membrane remodeling and epithelial branching morphogenesis in embryonic lung by Rho and cytoskeletal tension. Dev Dyn 232: 268-281.

Morrisey EE, Hogan BL. 2010. Preparing for the first breath: Genetic and cellular mechanisms in lung development. Dev Cell 18: 8-23.

Motoyama J, Liu J, Mo R, Ding Q, Post M, Hui CC. 1998. Essential function of Gli2 and Gli3 in the formation of lung, trachea and oesophagus. Nat Genet 20: 54-57.

Mucenski ML, Wert SE, Nation JM, Loudy DE, Huelsken J, Birchmeier W, Morrisey EE, Whitsett JA. 2003. $\beta$-Catenin is required for specification of proximal/distal cell fate during lung morphogenesis. J Biol Chem 278: 40231-40238.

Ng YS, Rohan R, Sunday ME, Demello DE, D’Amore PA. 2001. Differential expression of VEGF isoforms in mouse during development and in the adult. Dev Dyn 220: $112-121$.

Nogawa H, Morita K, Cardoso WV. 1998. Bud formation precedes the appearance of differential cell proliferation during branching morphogenesis of mouse lung epithelium in vitro. Dev Dyn 213: 228-235.

* Ochoa-Espinosa A, Affolter M. 2012. Branching morphogenesis: From cells to organs and back. Cold Spring Harb Perspect Biol doi: 10. 1101/cshperspect.a008243.

Okubo T, Knoepfler PS, Eisenman RN, Hogan BL. 2005. Nmyc plays an essential role during lung development as a dosage-sensitive regulator of progenitor cell proliferation and differentiation. Development 132: $1363-1374$.

Olson MF. 2004. Contraction reaction: Mechanical regulation of Rho GTPase. Trends Cell Biol 14: 111-114.

Parera MC, van Dooren M, van Kempen M, de Krijger R, Grosveld F, Tibboel D, Rottier R. 2005. Distal angiogenesis: A new concept for lung vascular morphogenesis. Am J Physiol Lung Cell Mol Physiol 288: L141-L149.

Park J, Zhang JJ, Moro A, Kushida M, Wegner M, Kim PC. 2010. Regulation of Sox 9 by Sonic Hedgehog (Shh) is essential for patterning and formation of tracheal cartilage. Dev Dyn 239: 514-526.

Partanen J, Puri MC, Schwartz L, Fischer KD, Bernstein A, Rossant J. 1996. Cell autonomous functions of the receptor tyrosine kinase TIE in a late phase of angiogenic capillary growth and endothelial cell survival during murine development. Development 122: 3013-3021.

Pepicelli CV, Lewis PM, McMahon AP. 1998. Sonic hedgehog regulates branching morphogenesis in the mammalian lung. Curr Biol 8: $1083-1086$.

Perl AK, Tichelaar JW, Whitsett JA. 2002a. Conditional gene expression in the respiratory epithelium of the mouse. Transgenic Res 11: 21-29.

Perl AK, Wert SE, Nagy A, Lobe CG, Whitsett JA. 2002b. Early restriction of peripheral and proximal cell lineages during formation of the lung. Proc Natl Acad Sci 99: 10482-10487.

Qi BQ, Beasley SW. 2000. Stages of normal tracheo-bronchial development in rat embryos: Resolution of a controversy. Dev Growth Differ 42: $145-153$.

Que J, Choi M, Ziel JW, Klingensmith J, Hogan BL. 2006. Morphogenesis of the trachea and esophagus: Current players and new roles for noggin and Bmps. Differentiation 74: 422-437.

Rajagopal J, Carroll TJ, Guseh JS, Bores SA, Blank LJ, Anderson WJ, Yu J, Zhou Q, McMahon AP, Melton DA. 2008. Wnt7b stimulates embryonic lung growth by coordinately increasing the replication of epithelium and mesenchyme. Development 135: 1625-1634.

Ramasamy SK, Mailleux AA, Gupte VV, Mata F, Sala FG, Veltmaat JM, Del Moral PM, De Langhe S, Parsa S, Kelly LK, et al. 2007. Fgf10 dosage is critical for the amplification of epithelial cell progenitors and for the formation of multiple mesenchymal lineages during lung development. Dev Biol 307: 237-247.

Rancourt DE, Tsuzuki T, Capecchi MR. 1995. Genetic interaction between hoxb- 5 and hoxb- 6 is revealed by nonallelic noncomplementation. Genes Dev 9: 108-122.

Rawlins EL. 2011. The building blocks of mammalian lung development. Dev Dyn 240: 463-476.

Rawlins EL, Okubo T, Que J, Xue Y, Clark C, Luo X, Hogan BL. 2008. Epithelial stem/progenitor cells in lung postnatal growth, maintenance, and repair. Cold Spring Harb Symp Quant Biol 73: 291-295.

Rawlins EL, Clark CP, Xue Y, Hogan BL. 2009. The Id2 ${ }^{+}$distal tip lung epithelium contains individual multipotent embryonic progenitor cells. Development 136: 3741-3745.

Robinson PD, Fitzgerald DA. 2007. Congenital diaphragmatic hernia. Paediatr Respir Rev 8: 323-334; quiz 334-325.

Rock JR, Hogan BL. 2011. Epithelial progenitor cells in lung development, maintenance, repair, and disease. Annu Rev Cell Dev Biol 27: $493-512$.

Sadler T. 2010. Formation of the lung buds. In Langman's medical embryology. Lippincott Williams \& Wilkins, Philadelphia.

Sakai T, Larsen M, Yamada KM. 2003. Fibronectin requirement in branching morphogenesis. Nature 423: 876-881.

Sakiyama J, Yokouchi Y, Kuroiwa A. 2000. Coordinated expression of Hoxb genes and signaling molecules during development of the chick respiratory tract. Dev Biol 227: 12-27.

Sakiyama J, Yamagishi A, Kuroiwa A. 2003. Tbx4-Fgf10 system controls lung bud formation during chicken embryonic development. Development 130: 1225-1234.

Sala FG, Del Moral PM, Tiozzo C, Alam DA, Warburton D, Grikscheit T, Veltmaat JM, Bellusci S. 2011. FGF10 controls the patterning of the tracheal cartilage rings via Shh. Development 138: 273-282.

Sato A, Yamamoto H, Sakane H, Koyama H, Kikuchi A. 2010. Wnt5a regulates distinct signalling pathways by binding to Frizzled2. EMBOJ 29: $41-54$.

Schachtner SK, Wang Y, Scott Baldwin H. 2000. Qualitative and quantitative analysis of embryonic pulmonary vessel formation. Am J Respir Cell Mol Biol 22: 157-165.

Sekine K, Ohuchi H, Fujiwara M, Yamasaki M, Yoshizawa T, Sato T, Yagishita N, Matsui D, Koga Y, Itoh N, et al. 1999. Fgf10 is essential for limb and lung formation. Nat Genet 21: 138-141.

Shi W, Zhao J, Anderson KD, Warburton D. 2001. Gremlin negatively modulates BMP-4 induction of embryonic mouse lung branching morphogenesis. Am J Physiol Lung Cell Mol Physiol 280: L1030L1039.

Shu W, Jiang YQ, Lu MM, Morrisey EE. 2002. Wnt7b regulates mesenchymal proliferation and vascular development in the lung. Development 129: 4831-4842.

Shu W, Guttentag S, Wang Z, Andl T, Ballard P, Lu MM, Piccolo S, Birchmeier W, Whitsett JA, Millar SE, et al. 2005. Wnt/ $\beta$-catenin signaling acts upstream of N-myc, BMP4, and FGF signaling to regulate proximal-distal patterning in the lung. Dev Biol 283: 226-239.

Spooner BS, Wessells NK. 1970. Mammalian lung development: Interactions in primordium formation and bronchial morphogenesis. J Exp Zool 175: 445-454.

Stone KC, Mercer RR, Gehr P, Stockstill B, Crapo JD. 1992. Allometric relationships of cell numbers and size in the mammalian lung. Am J Respir Cell Mol Biol 6: 235-243.

Sun J, Chen H, Chen C, Whitsett JA, Mishina Y, Bringas P Jr, Ma JC, Warburton D, Shi W. 2008. Prenatal lung epithelial cell-specific abrogation of Alk3-bone morphogenetic protein signaling causes neonatal respiratory distress by disrupting distal airway formation. Am J Pathol 172: $571-582$.

Tang N, Marshall WF, McMahon M, Metzger RJ, Martin GR. 2011. Control of mitotic spindle angle by the RAS-regulated ERK1/2 pathway determines lung tube shape. Science 333: 342-345. 
Taniguchi K, Ayada T, Ichiyama K, Kohno R, Yonemitsu Y, Minami Y, Kikuchi A, Maehara Y, Yoshimura A. 2007. Sprouty2 and Sprouty4 are essential for embryonic morphogenesis and regulation of FGF signaling. Biochem Biophys Res Commun 352: 896-902.

Tefft JD, Lee M, Smith S, Leinwand M, Zhao J, Bringas P Jr, Crowe DL, Warburton D. 1999. Conserved function of mSpry-2, a murine homolog of Drosophila sprouty, which negatively modulates respiratory organogenesis. Curr Biol 9: 219-222.

Ten Have-Opbroek AA. 1981. The development of the lung in mammals: An analysis of concepts and findings. Am J Anat 162: 201-219.

Thurlebeck WM. 1995. Lung growth and development. In Pathology of the lung (ed. Thurlebeck WM, Churg AM), pp. 37-87. Theime Medical Publishers, New York.

Tian Y, Zhang Y, Hurd L, Hannenhalli S, Liu F, Lu MM, Morrisey EE. 2011. Regulation of lung endoderm progenitor cell behavior by miR302/367. Development 138: 1235-1245.

Tollet J, Everett AW, Sparrow MP. 2001. Spatial and temporal distribution of nerves, ganglia, and smooth muscle during the early pseudoglandular stage of fetal mouse lung development. Dev Dyn 221: 48-60.

Tsao PN, Vasconcelos M, Izvolsky KI, Qian J, Lu J, Cardoso WV. 2009. Notch signaling controls the balance of ciliated and secretory cell fates in developing airways. Development 136: 2297-2307.

Unbekandt M, del Moral PM, Sala FG, Bellusci S, Warburton D, Fleury V. 2008. Tracheal occlusion increases the rate of epithelial branching of embryonic mouse lung via the FGF10-FGFR2b-Sprouty2 pathway. Mech Dev 125: 314-324.

Valencik ML, McDonald JA. 2001. Codon optimization markedly improves doxycycline regulated gene expression in the mouse heart. Transgenic Res 10: 269-275.

van Tuyl M, Groenman F, Wang J, Kuliszewski M, Liu J, Tibboel D, Post M. 2007. Angiogenic factors stimulate tubular branching morphogenesis of sonic hedgehog-deficient lungs. Dev Biol 303: 514-526.

Ventura A, Young AG, Winslow MM, Lintault L, Meissner A, Erkeland SJ, Newman J, Bronson RT, Crowley D, Stone JR, et al. 2008. Targeted deletion reveals essential and overlapping functions of the miR-17 through 92 family of miRNA clusters. Cell 132: 875-886.

Volpe MV, Ramadurai SM, Pham LD, Nielsen HC. 2007. Hoxb-5 down regulation alters Tenascin-C, FGF10 and Hoxb gene expression patterns in pseudoglandular period fetal mouse lung. Front Biosci 12: $860-873$.

Wang Z, Shu W, Lu MM, Morrisey EE. 2005. Wnt7b activates canonical signaling in epithelial and vascular smooth muscle cells through interactions with Fzd1, Fzd10, and LRP5. Mol Cell Biol 25: 5022-5030.

Wang Z, Dolle P, Cardoso WV, Niederreither K. 2006. Retinoic acid regulates morphogenesis and patterning of posterior foregut derivatives. Dev Biol 297: 433-445.

Warburton D. 2008. Developmental biology: Order in the lung. Nature 453: 733-735.

Warburton D, Bellusci S, De Langhe S, Del Moral PM, Fleury V, Mailleux A, Tefft D, Unbekandt M, Wang K, Shi W. 2005. Molecular mechanisms of early lung specification and branching morphogenesis. $P e$ diatr Res 57: 26R-37R.
Warburton D, El-Hashash A, Carraro G, Tiozzo C, Sala F, Rogers O, De Langhe S, Kemp PJ, Riccardi D, Torday J, et al. 2010. Lung organogenesis. Curr Top Dev Biol 90: 73-158.

Weaver M, Yingling JM, Dunn NR, Bellusci S, Hogan BL. 1999. Bmp signaling regulates proximal-distal differentiation of endoderm in mouse lung development. Development 126: 4005-4015.

Weaver M, Dunn NR, Hogan BL. 2000. Bmp4 and Fgf10 play opposing roles during lung bud morphogenesis. Development 127: 2695-2704.

Weaver M, Batts L, Hogan BL. 2003. Tissue interactions pattern the mesenchyme of the embryonic mouse lung. Dev Biol 258: 169-184.

White AC, Xu J, Yin Y, Smith C, Schmid G, Ornitz DM. 2006. FGF9 and SHH signaling coordinate lung growth and development through regulation of distinct mesenchymal domains. Development 133: $1507-1517$

White AC, Lavine KJ, Ornitz DM. 2007. FGF9 and SHH regulate mesenchymal Vegfa expression and development of the pulmonary capillary network. Development 134: 3743-3752.

Williams AK, Quan QB, Beasley SW. 2003. Three-dimensional imaging clarifies the process of tracheoesophageal separation in the rat. $J \mathrm{Pe}$ diatr Surg 38: 173-177.

Williams AE, Moschos SA, Perry MM, Barnes PJ, Lindsay MA. 2007. Maternally imprinted microRNAs are differentially expressed during mouse and human lung development. Dev Dyn 236: 572-580.

Yates LL, Schnatwinkel C, Murdoch JN, Bogani D, Formstone CJ, Townsend S, Greenfield A, Niswander LA, Dean CH. 2010. The PCP genes Celsr1 and Vangl2 are required for normal lung branching morphogenesis. Hum Mol Genet 19: 2251-2267.

Yi L, Domyan ET, Lewandoski M, Sun X. 2009. Fibroblast growth factor 9 signaling inhibits airway smooth muscle differentiation in mouse lung. Dev Dyn 238: 123-137.

Yin Y, White AC, Huh SH, Hilton MJ, Kanazawa H, Long F, Ornitz DM. 2008. An FGF-WNT gene regulatory network controls lung mesenchyme development. Dev Biol 319: 426-436.

Yin Y, Wang F, Ornitz DM. 2011. Mesothelial and epithelial derived FGF9 have distinct functions in the regulation of lung development. Development 138: 3169-3177.

Yu K, Xu J, Liu Z, Sosic D, Shao J, Olson EN, Towler DA, Ornitz DM. 2003. Conditional inactivation of FGF receptor 2 reveals an essential role for FGF signaling in the regulation of osteoblast function and bone growth. Development 130: 3063-3074.

Zakin LD, Mazan S, Maury M, Martin N, Guenet JL, Brulet P. 1998. Structure and expression of Wnt13, a novel mouse Wnt2 related gene. Mech Dev 73: 107-116.

Zhang S, Lin Y, Itaranta P, Yagi A, Vainio S. 2001. Expression of Sprouty genes 1, 2 and 4 during mouse organogenesis. Mech Dev 109: $367-$ 370.

Zhang Y, Goss AM, Cohen ED, Kadzik R, Lepore JJ, Muthukumaraswamy K, Yang J, DeMayo FJ, Whitsett JA, Parmacek MS, et al. 2008. A Gata6Wnt pathway required for epithelial stem cell development and airway regeneration. Nat Genet 40: 862-870.

Zhao L, Wang K, Ferrara N, Vu TH. 2005. Vascular endothelial growth factor co-ordinates proper development of lung epithelium and vasculature. Mech Dev 122: 877-886. 


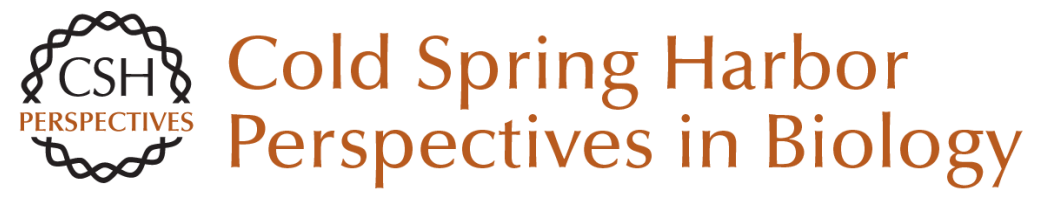

\section{Signaling Networks Regulating Development of the Lower Respiratory Tract}

David M. Ornitz and Yongjun Yin

Cold Spring Harb Perspect Biol 2012; doi: 10.1101/cshperspect.a008318

Subject Collection Mammalian Development

The Dynamics of Morphogenesis in the Early

Mouse Embryo

Jaime A. Rivera-Pérez and Anna-Katerina

Hadjantonakis

microRNAs as Developmental Regulators Kathryn N. Ivey and Deepak Srivastava

Development of the Endochondral Skeleton Fanxin Long and David M. Ornitz

Adipogenesis Kelesha Sarjeant and Jacqueline M. Stephens

Molecular Mechanisms of Inner Ear Development Doris K. Wu and Matthew W. Kelley

Polarity in Mammalian Epithelial Morphogenesis Julie Roignot, Xiao Peng and Keith Mostov

Eye Development and Retinogenesis Whitney Heavner and Larysa Pevny

Primordial Germ Cells in Mice Mitinori Saitou and Masashi Yamaji
Cell Division Modes and Cleavage Planes of

Neural Progenitors during Mammalian Cortical Development

Fumio Matsuzaki and Atsunori Shitamukai

Blood and Lymphatic Vessel Formation Victoria L. Bautch and Kathleen M. Caron

Transcriptional Networks in Liver and Intestinal Development Karyn L. Sheaffer and Klaus H. Kaestner

Pluripotency in the Embryo and in Culture Jennifer Nichols and Austin Smith

Signaling and Transcriptional Networks in Heart Development and Regeneration

Benoit G. Bruneau

Signals and Switches in Mammalian Neural Crest Cell Differentiation Shachi Bhatt, Raul Diaz and Paul A. Trainor

Hematopoiesis Michael A. Rieger and Timm Schroeder

Intercellular Interactions, Position, and Polarity in Establishing Blastocyst Cell Lineages and Embryonic Axes

Robert O. Stephenson, Janet Rossant and Patrick P.L. Tam

For additional articles in this collection, see http://cshperspectives.cshlp.org/cgi/collection/

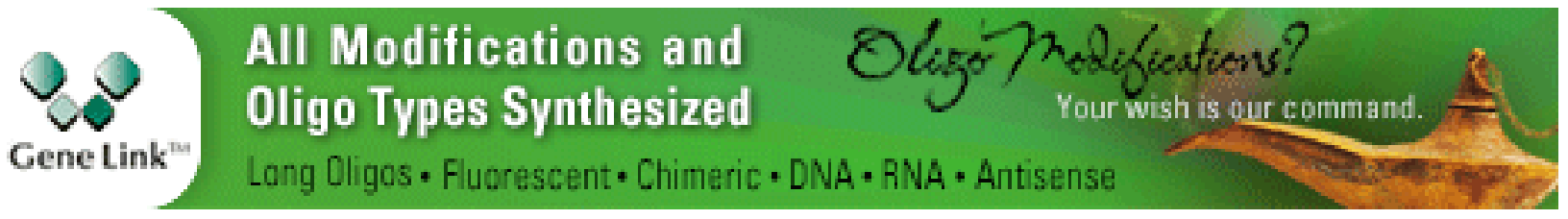

Copyright @ 2012 Cold Spring Harbor Laboratory Press; all rights reserved 
For additional articles in this collection, see http://cshperspectives.cshlp.org/cgi/collection/

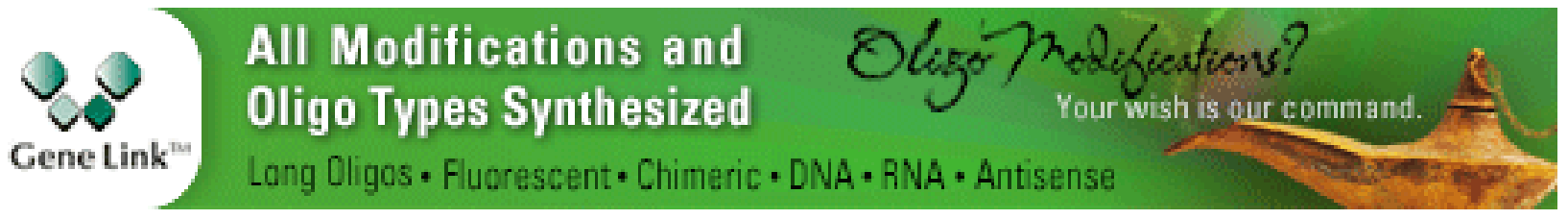

Copyright @ 2012 Cold Spring Harbor Laboratory Press; all rights reserved 